University of Wollongong

Research Online

Faculty of Engineering and Information

Faculty of Engineering and Information

Sciences - Papers: Part A

Sciences

$1-1-2014$

\title{
Enhancement of removal of trace organic contaminants by powdered activated carbon dosing into membrane bioreactors
}

\author{
Ngoc Luong Nguyen \\ University of Wollongong, Inn909@uowmail.edu.au \\ Faisal Ibney Hai \\ University of Wollongong, faisal@uow.edu.au \\ Long Nghiem \\ University of Wollongong, longn@uow.edu.au \\ Jinguo Kang \\ University of Wollongong, jkang@uow.edu.au \\ William Price \\ University of Wollongong, wprice@uow.edu.au
}

See next page for additional authors

Follow this and additional works at: https://ro.uow.edu.au/eispapers

Part of the Engineering Commons, and the Science and Technology Studies Commons

Research Online is the open access institutional repository for the University of Wollongong. For further information contact the UOW Library: research-pubs@uow.edu.au 


\title{
Enhancement of removal of trace organic contaminants by powdered activated carbon dosing into membrane bioreactors
}

\begin{abstract}
This study compared the removal efficiency of 22 widespread trace organic contaminants by a laboratoryscale membrane bioreactor (MBR) with and without direct addition of powdered activated carbon (PAC) into the activated sludge reactor over a period of 312 days. The removal of hydrophilic and biologically persistent trace organic contaminants was immediately improved to above $95 \%$ after the addition of PAC into MBR. However, a compound-specific gradual decrease in removal underscored the requirement for the addition of fresh PAC. Adsorption onto PAC-added sludge appeared to play a significant role in the relatively more effective aqueous phase removal of a few resistant compounds such as carbamazepine in this study. A slower reduction in removal efficiency of compounds showing extraordinary persistence such as fenoprop and diclofenac was observed after raising the PAC concentration in the MBR from 0.1 to 0.5. $\mathrm{g} / \mathrm{L}$. Nevertheless, comparison of extent of removal in terms of PAC usage indicated the suitability of more frequent dosing of smaller amounts of PAC. 2013 Taiwan Institute of Chemical Engineers.
\end{abstract}

\section{Keywords}

powdered, removal, activated, carbon, dosing, into, membrane, bioreactors, trace, organic, contaminants, enhancement

Disciplines

Engineering | Science and Technology Studies

\section{Publication Details}

Nguyen, L., Hai, F. I., Nghiem, L. D., Kang, J., Price, W. E., Park, C. \& Yamamoto, K. (2014). Enhancement of removal of trace organic contaminants by powdered activated carbon dosing into membrane bioreactors. Journal of the Taiwan Institute of Chemical Engineers, 45 (2), 571-578.

\section{Authors}

Ngoc Luong Nguyen, Faisal Ibney Hai, Long Nghiem, Jinguo Kang, William Price, Chul Park, and Kazuo Yamamoto 


\section{Enhancement of removal of trace organic contaminants by powdered activated carbon dosing into membrane bioreactors}

Journal of the Taiwan Institute of Chemical Engineers 45 (2014) 571-578

Luong N. Nguyen ${ }^{\mathrm{a}}$, Faisal I. Hai ${ }^{\mathrm{a},}$, Long D. Nghiem ${ }^{\mathrm{a}}$, Jinguo Kang ${ }^{\mathrm{a}, \mathrm{b}}$, William E. Price ${ }^{\mathrm{b}}$, Chul Park ${ }^{\mathrm{c}}$ and Kazuo Yamamoto ${ }^{\mathrm{d}}$

a Strategic Water Infrastructure Laboratory, School of Civil, Mining and Environmental Engineering, University of Wollongong, Wollongong, NSW 2522, Australia

${ }^{\mathrm{b}}$ Strategic Water Infrastructure Laboratory, School of Chemistry, University of Wollongong, Wollongong, NSW 2522, Australia

${ }^{c}$ Department of Civil and Environmental Engineering, University of Massachusetts, Amherst, MA 01003, United States

${ }^{\mathrm{d}}$ Environmental Science Center, The University of Tokyo, 7-3-1 Hongo, Bunkyo-ku, Tokyo, 113-0033, Japan

* Corresponding author: Faisal I. Hai, Email: faisal@uow.edu.au, Ph +61 242213054 


\section{RESEARCH HIGHLIGHTS}

- PAC addition into MBR initially resulted in high removal of all 22 trace organics.

- PAC saturation led to gradual drop in removal of 7 hydrophilic and resistant organics.

- Notable among these 7 hydrophilic and resistant organics are fenoprop and diclofenac.

- Frequent but smaller dose addition is recommended for efficient PAC use. 


\section{Abstract}

This study compared the removal efficiency of 22 widespread trace organic contaminants by a laboratory-scale membrane bioreactor (MBR) with and without direct addition of powdered activated carbon (PAC) into the activated sludge reactor over a period of 312 days. The removal of hydrophilic and biologically persistent trace organic contaminants was immediately improved to above $95 \%$ after the addition of PAC into MBR. However, a compound-specific gradual decrease in removal underscored the requirement for the addition of fresh PAC. Adsorption onto PAC-added sludge appeared to play a significant role in the relatively more effective aqueous phase removal of a few resistant compounds such as carbamazepine in this study. A slower reduction in removal efficiency of compounds showing extraordinary persistence such as fenoprop and diclofenac was observed after raising the PAC concentration in the MBR from 0.1 to $0.5 \mathrm{~g} / \mathrm{L}$. Nevertheless, comparison of extent of removal in terms of PAC usage $(120 \mathrm{~L}$ effluent/g PAC) indicated the suitability of more frequent dosing of smaller amounts of PAC.

Key words: Membrane bioreactor (MBR); adsorption; powdered activated carbon (PAC); trace organic contaminants; water recycling. 


\section{Introduction}

A great number of natural and anthropogenic trace organic contaminants have been detected in raw sewage and sewage-impacted water bodies all over the world at concentrations up to a few $\mu \mathrm{g} / \mathrm{L}$ [1]. These trace organic contaminants include pharmaceutically active compounds ( $\mathrm{PhACs}$ ), steroid hormones, pesticides and industrial chemicals and their metabolites. Given their potential adverse effects on human and other biota, their removal is of utmost importance to protect the environment and ensure provision of safe drinking water. However, because the conventional water and wastewater treatment processes were not designed with this specific aim, effective removal of all kinds of trace organic contaminants cannot be expected by these [2].

Membrane bioreactors (MBRs) demonstrate superior performance over conventional activated sludge (CAS) processes in terms of basic effluent quality parameters [3]. By compactly combining a bioreactor with membrane filtration units, MBR has the potential to produce effluent suitable for reuse. Thus there has been considerable research effort on the assessment of trace organic contaminant removal by MBR treatment. Research suggests that compared to CAS, MBR often results in better and/or more stable removal of trace organic contaminants possessing moderate to high biodegradability [2]. However, significant variation in MBR removal performance, particularly for biologically persistent hydrophilic compounds, has been noted in several recent studies [4-6]. Strategies explored in recent studies to enhance the removal of trace organic contaminants include fine tuning of operational parameters such as hydraulic retention time (HRT), sludge retention time (SRT) [7, 8], $\mathrm{pH}[9]$ and temperature [10]. Adsorption on activated sludge, potentially followed by biodegradation is the main mechanism that accounts for the removal of trace organic contaminants by $\operatorname{MBR}[2,4,6,11]$. A way to increase adsorption of trace organic contaminants is to add powdered activated carbon (PAC) or granular activated carbon (GAC) to the bioreactor. It has been also suggested that a significant increase in the retention of soluble 
contaminants onto PAC-added sludge may enhance the biodegradation of slowly biodegradable compounds [12].

A number of studies have investigated the application of PAC within an MBR (PAC-MBR) in relation to membrane fouling mitigation [13-15]. Despite the likelihood of enhanced biodegradation of biologically persistent organic compounds in a PAC-MBR system, few of them have, in fact, assessed or reported on this aspect. To date, PAC-MBRs have been explored with different sources of wastewater [12, 16-19], but only a few studies have specifically explored PAC-MBR for the removal of trace organic contaminants [20-23]. In addition, some studies have explored adsorption of contaminants on either PAC [24] or GAC [25] as a post treatment following MBR treatment with encouraging results. Previously reported data confirmed enhanced removal of selected biologically persistent trace organic contaminants from aqueous phase by adding PAC into MBR. However, a comprehensive understanding of the phenomena involved, particularly the simultaneous effect of PAC dose and the physicochemical properties of a range of compounds, are yet to be elucidated.

The aim of this study is to compare the long-term removal efficiency of 22 selected trace organic contaminants from a synthetic municipal wastewater by both MBR alone and direct addition of PAC into MBR (PAC-MBR). The addition of PAC into MBR was assessed as a potential tool to provide additional removal capacity for persistent trace organic contaminants. Special focus was given to the effect of the PAC dose and the physicochemical properties of the trace organic contaminants on their removal efficiency by the PAC-MBR system. In addition to information regarding removal from aqueous phase, the extent of adsorption of the target compounds onto sludge is also investigated. 


\section{Materials and Methods}

\subsection{Model trace organic contaminants and synthetic wastewater}

A set of 22 trace organic contaminants (Table 1) representing four major groups, namely, PhACs, steroid hormones, pesticides and industrial chemicals and their metabolites were selected for investigation based on their widespread occurrence in raw sewage and sewage-impacted water bodies $[1,2,4]$. These contaminants have been detected in domestic sewage at a concentration of up to a few $\mu \mathrm{g} / \mathrm{L}[1,2,4]$. In this study, the trace organic contaminants were introduced to the feed solution to achieve a constant concentration of approximately $5 \mu \mathrm{g} / \mathrm{L}$ of each compound. A stock solution of all of the selected compounds was prepared in pure methanol at a concentration of $1 \mathrm{~g} / \mathrm{L}$ each on a monthly basis and stored at $-18{ }^{\circ} \mathrm{C}$. This stock solution was then used to prepare the synthetic wastewater.

A synthetic wastewater comprising of glucose $(400 \mathrm{mg} / \mathrm{L})$, peptone $(100 \mathrm{mg} / \mathrm{L})$, urea $(35 \mathrm{mg} / \mathrm{L})$, $\mathrm{KH}_{2} \mathrm{PO}_{4}(17.5 \mathrm{mg} / \mathrm{L}), \mathrm{MgSO}_{4}(17.5 \mathrm{mg} / \mathrm{L}), \mathrm{FeSO}_{4}(10 \mathrm{mg} / \mathrm{L})$ and sodium acetate $(225 \mathrm{mg} / \mathrm{L})$ was utilized. [25]. The total organic carbon (TOC), total nitrogen (TN) and chemical oxygen demand (COD) of the wastewater were approximately 180, 25 and $600 \mathrm{mg} / \mathrm{L}$, respectively.

\section{TABLE 1}

\subsection{Laboratory scale MBR system and experimental protocol}

A laboratory scale MBR system (Supplementary Data Figure S2) consisting of a 4.5 L (active volume) glass reactor was employed. A hydrophilized PVDF hollow fibre membrane module (Mitsubishi Rayon Engineering, Japan) with a membrane nominal pore size of $0.4 \mu \mathrm{m}$ and a total surface area of $0.074 \mathrm{~m}^{2}$ was submerged into the reactor. As the main focus of this study was on trace organic contaminant removal performance, a stable hydraulic performance under minimised membrane fouling was highly desirable and, owing to the small reactor volume, any periodic in situ membrane backwashing would significantly dilute the reactor media. Therefore, the membrane was 
operated under a low average membrane flux such that significant membrane fouling, requiring periodic cleaning, could be avoided. The membrane was operated on a 14 min "suction" and 1 min “relaxation" cycle under an average flux of $2.7 \mathrm{~L} / \mathrm{m}^{2} . h$, resulting in a hydraulic retention time of 24 h. Notably, the flux and HRT used in this study are similar to those in the study of Lesage et al. [17]. The transmembrane pressure (TMP) was continuously monitored using a high-resolution $( \pm$ $0.1 \mathrm{kPa}$ ) pressure sensor (SPER scientific 840064, Extech equipment Pty. Ltd, Victoria, Australia) to detect probable onset of fouling. During continuous operation without any routine cleaning, exsitu chemical cleaning had to be performed only twice (on day 186 and 306) over the whole operation period (312 days). During ex-situ cleaning, the membrane was soaked into sodium hypochlorite solution ( $0.5 \mathrm{~g}$ active chlorine per litre) for $60 \mathrm{~min}$ and then backwashed with a freshly prepared sodium hypochlorite solution at a flux of $9 \mathrm{~L} / \mathrm{m}^{2} . \mathrm{h}$ for $30 \mathrm{~min}$.

The reactor was seeded with activated sludge from another laboratory scale MBR system which had been running for over 3 years. The synthetic wastewater (containing the trace organic contaminants along with the other nutrients, see section 2.1) was added continuously into the reactor via a feed pump at flow rate of $3.1 \mathrm{~mL} / \mathrm{mim}$. Air was supplied via a diffuser located at the bottom of the aeration tank to maintain dissolved oxygen (DO) concentration at $4 \pm 1 \mathrm{mg} / \mathrm{L}$ throughout the operating period. The temperature of the mixed liquor was maintained at $22.0 \pm 0.1$ ${ }^{\circ} \mathrm{C}$ and the $\mathrm{pH}$ of the mixed liquor remained stable within the range of 7.2-7.5.

The experiment was conducted over a total 312 days, with a 51 day start-up period, 153 days of MBR-only operation and 100 days of operation in PAC-MBR mode (Supplementary Data Table S3). This protocol of stepwise assessment of performance in the same bioreactor, first without PAC and then with PAC, is in line with that in previous studies $[17,20]$. At the end of the start-up phase, the 22 trace organic contaminants were added to the synthetic wastewater. In order to minimize loss of trace organic contaminants with wasted sludge, apart from the samples for mixed liquor suspended solid (MLSS) and mixed liquor volatile suspended solid (MLVSS) measurement, no sludge was withdrawn from the MBR up to day 196, by which time the MLSS concentration had 
increased from 5 to $11.5 \mathrm{~g} / \mathrm{L}$. However, sludge was withdrawn on day 197 to reduce the MLSS concentration to $6 \mathrm{~g} / \mathrm{L}$ prior to addition of PAC. Sludge withdrawal at this point was performed because more frequent membrane fouling may have been encountered if the operation was continued under a high MLSS concentration, which would have hindered the assessment of the effect of PAC addition into the MBR on trace organic contaminant removal. For nine days following the sludge withdrawal, TOC, TN as well as the trace organic contaminant removal performance was closely monitored to confirm stable performance. PAC (PAC-1000, Activated Carbon Technologies Pty. Ltd, Australia) (Table 2) was added directly to the reactor, first on day 206 (0.45 g PAC) and subsequently on day 243 (additional $1.8 \mathrm{~g}$ PAC) of continuous operation to obtain PAC concentrations of 0.1 and $0.5 \mathrm{~g} / \mathrm{L}$, respectively. After PAC addition, the PAC-MBR was operated in the same fashion as for MBR-only, with the operating conditions such as membrane flux, HRT, DO concentration, $\mathrm{pH}$ and temperature remaining the same. MLSS concentration was the only exception; however, the negligible effect of MLSS concentration on the biological performance has been discussed in Section 3.1 and 3.3.

\section{TABLE 2}

\subsection{Analysis of trace organic contaminants and other basic parameters}

The performance of the MBR and PAC - MBR systems were compared in terms of trace organic contaminants and TOC/TN removal efficiency. Operating parameters, namely, MLSS and MLVSS concentration, turbidity, sludge volume index (SVI) and specific oxygen uptake rate (SOUR) were also monitored to confirm process stability. Basic parameters including TOC, TN, turbidity, MLSS/MLVSS, SVI and SOUR were measured according to the Standard Methods for the Examination of Water and Wastewater [26] and methods utilised in our previous studies [6, 10].

Duplicate samples of both influent and effluent were taken once a week for trace organic contaminant analysis throughout the operating period. The concentration of target organic contaminants in MBR influent and permeate samples was measured by a previously reported [10] analytical technique involving solid phase extraction, derivatisation and quantitative determination 
by a Shimadzu GC/MS (QP5000) system equipped with a Shimadzu AOC 20i autosampler. A Phenomenex Zebron ZB-5 (5\% diphenyl-95\% dimethylpolysiloxane) capillary column (30 m $\times$ $\left.0.25 \mathrm{~mm} \mathrm{ID}, \mathrm{d}_{\mathrm{f}}=0.25 \mu \mathrm{m}\right)$ was used. The quantitative detection limits of this analytical method were compound specific and in the range from 1 to $20 \mathrm{ng} / \mathrm{L}$ (Supplementary Data Table S4). Removal efficiency was calculated as $R=100 \times\left(1-\frac{C_{E f f}}{C_{I n f}}\right)$, where $\mathrm{C}_{\mathrm{Inf}}$ and $\mathrm{C}_{\mathrm{Eff}}$ are influent and effluent (permeate) concentrations of the trace organic contaminants, respectively.

\section{Results and discussion}

\subsection{Sludge characteristics}

\subsubsection{MLSS concentration}

During the first 205 days of MBR operation, the MLSS concentration in the reactor increased gradually from 3.2 to $11.5 \mathrm{~g} / \mathrm{L}$. However, after PAC was added to the reactor, no significant changes in MLSS concentration were observed apart from a slight decrease toward the end of the experiment. Our observation is in line with that of Lesage et al. [17] who reported slower MLSS build up following PAC addition to MBR. Seker et al. [27] also reported slower sludge production rate in case of a biofilm developed on activated carbon surface as compared to a suspended culture. They attributed this to insufficient substrate transfer to the inner region of the biofilm. Notably, the ratio of MLVSS/MLSS was stable throughout the period of MBR and PAC - MBR operation (Table 3). During operation without PAC, in an MLSS concentration range of 3.2 to $11.5 \mathrm{~g} / \mathrm{L}$, no significant difference was observed in TOC/TN (Section 3.3) and trace organic contaminant removal (except for seven resistant trace organics which showed variable removal throughout the MBR-only operation, Section 3.4). Therefore, the effect of slight change in MLSS concentration on removal performance during PAC-MBR operation can be considered negligible.

TABLE 3 


\subsubsection{Turbidity, sludge volume index and specific oxygen uptake rate}

In an MBR, an increase in supernatant turbidity may be associated with sludge deflocculation which may have impacts on both membrane fouling and removal performance [10]. In our study, slightly higher levels of SVI and supernatant turbidity were observed at the beginning of MBR operation (Table 3). This might be expected given the more dispersed nature of any flocs and, hence, poorer settling properties at the beginning of MBR operation [22]. SVI and supernatant turbidity values decreased significantly after 100 days of operation and remained stable through to the end of the operation period. This suggests stable sludge flocs were formed during the majority of the experiment when removal of trace organic contaminants was monitored. Previous studies have reported that addition of PAC into MBR can enhance flocs formation [17, 22] and sludge settling. Nevertheless, in this study no significant change in SVI value was observed after PAC addition as the sludge had already achieved good settleability beforehand.

SOUR can be used to assess microbial activities at different periods of operation of a biological reactor [28]. In this study, the SOUR values varied slightly before and after addition of PAC (Table 3). Stable operating conditions (Table 3) helped achieve continuous biological stability as suggested by supernatant turbidity, SVI and SOUR (Table 3), and the stability of biological performance is further supported by the consistency of TOC and TN removal levels (Section 3.3).

\subsection{TMP profile}

As noted in section 2.2, except for periodic relaxation (14 min on and $1 \mathrm{~min}$ off), in this study, no regular backwashing was applied to avoid dilution of the reactor media. Although a very low average membrane flux was applied to minimise fouling under the circumstances, flux and TMP were recorded throughout this work to detect any abrupt changes.

As can be seen in Supplementary Data Figure S4, TMP remained stable during the 51 day start-up period. No abnormal TMP-increase was observed following the introduction of the trace organic contaminants to the feed solution. Direct addition of PAC into an MBR has been widely reported to 
mitigate membrane fouling via several mechanisms including adsorption of membrane foulants on PAC, scouring action of PAC, changing the composition and permeability of the cake layer and improved flocculation of MLSS [14, 15, 29]. By contrast, a few studies have reported that the addition of PAC directly into MBR does not improve membrane performance [12] but can rather promote membrane fouling $[30,31]$. In our study, vigorous aeration was applied to maintain an adequate DO level within the reactor and avoid settling of sludge at the corners of the reactor. However, as the reactor design was not hydrodynamically optimised, this mixing was found to be insufficient to avoid settling of sludge at certain locations in the reactor and accumulation of sludge onto the membrane surface. One can notice from Supplementary Data Figure S5 that a cake layer appeared to cover more membrane area during the operation with PAC. Greater coverage of the membrane area by a cake layer may be one reason why PAC addition resulted in slightly faster TMP-rise in the current study. By comparing two MBRs operated in parallel with 0.75 and $1.5 \mathrm{~g} / \mathrm{L}$ PAC, Ying et al. [31] attributed the faster TMP increase in case of the higher PAC dose to the increased probability of PAC particles depositing on the membrane surface. Drawing any conclusions about the role of PAC on the mitigation of membrane fouling is beyond the scope of this study. However, because the variation in TMP was not significantly different before and after PAC addition, the effect of TMP on the observed trace organic contaminant removal trends can be considered negligible.

\subsection{TOC and TN removal}

The removal efficiencies of both $\mathrm{TOC}$ and $\mathrm{TN}$ remained relatively constant during the entire experiment (Figure 1) despite considerable variation in MLSS concentration in the reactor (Section 3.1.1). The high removal of TOC irrespective of MLSS concentration was in good agreement with previous literature [9]. It is also worth noting that the removal of TOC did not deteriorate after adding the trace organic contaminants in the synthetic wastewater. A similar observation was made by $\mathrm{Li}$ et al. [20] who found that continuous high dosing $(750 \mu \mathrm{g} / \mathrm{L})$ of trace organic contaminants 
(carbamazepine and sulfamethoxazole) to the feed solution for extended periods did not have any discernible adverse effect on TOC and TN removal.

TOC removal was already $98 \pm 2 \%$ before the addition of PAC, and this was little changed under the PAC - MBR system. By contrast, the removal of TN in this study was $46 \pm 15 \%$. This, however, was expected as the MBR contained no anoxic zone to support simultaneous nitrification and denitrification. It has been previously reported that PAC shows negligible removal of ammonium containing compounds through physical adsorption due to their high polarity and solubility in water [32]. In line with the report of Sagabo et al. [32], no discernible increase in TN removal after addition of PAC was noticed in this study.

\section{FIGURE 1}

\subsection{Removal of trace organic contaminants}

\subsubsection{Removal by MBR-only treatment}

Possible removal mechanisms for trace organic contaminants during MBR treatment include biodegradation, adsorption to the biomass, volatilisation and physical retention by the membrane $[2,4,6]$. With a nominal pore size of about $0.4 \mu \mathrm{m}$, the membrane used in this study was not expected to directly retain any trace organic contaminants. In addition, given the very low Henry's constant $(\mathrm{H})$ and low $\mathrm{H} / \log \mathrm{D}$ ratio for all compounds selected in this study (Table 1), their removal by volatilisation was expected to be negligible. Therefore, adsorption onto sludge (and subsequent retention by membrane) and biodegradation can be considered to be the two main mechanisms responsible for the removal of trace organic contaminants in this study.

In good agreement with several previous studies [2, 4, 6, 33], we observed greater than $90 \%$ removal of four steroid hormones (estrone, 17- $\alpha$-ethynylestradiol, 17- $\beta$-estradiol and 17- $\beta$ estradiol-17-acetate), four alkyl phenolic surfactant and industrial compounds (bisphenol A, 4-tertbutylphenol, 4-tert-octyphenol and 4-n-nonylphenol) and a phenolic personal care product (triclosan). All of these steroid hormones and phenolic compounds possess significant hydrophobicity $(\log D>3.2)$. It has been suggested previously that removal of hydrophobic 
compounds is dominated by adsorption on sludge which may facilitate subsequent biodegradation $[6,34]$. On the other hand, there was a significant variation between the removal efficiencies of the hydrophilic compounds $(\log D<3.2)$. According to a simple quantitative framework proposed by Tadkaew et al. [6], electron withdrawing and donating functional groups play an important role in determining the extent of biodegradation, and, thus, the overall removal of the hydrophilic compounds. In the current work, of the 13 hydrophilic trace organic contaminants $(\log D<3.2)$, metronidazole, fenoprop, ketoprofen, naproxen, diclofenac, carbamazepine and pentachlorophenol were particularly resistant to MBR treatment (Figure 2), possibly due to the presence of one or more strong electron withdrawing functional groups (e.g. chlorine, amide and carboxylic) and/or absence of strong electron donating functional groups (e.g. hydroxyl). This is in good agreement with previously reported data $[2,4,6,10]$.

\section{FIGURE 2}

\subsubsection{Removal by PAC-MBR system}

\subsubsection{Removal using a PAC concentration of $0.1 \mathrm{~g} / \mathrm{L}$}

Results shown in Figure 2 highlight the limitation of MBR treatment in removing hydrophilic and biologically persistent trace organic contaminants. Similar to the performance of the MBR-only treatment, a high degree of removal $(>95 \%)$ of all hydrophobic compounds $(\log D>3.2)$ and six hydrophilic compounds (salicylic acid, acetaminophen, primidone, ibuprofen, gemfibrozil and estriol), was observed in the PAC - MBR system (Figure 2). More importantly, after adding PAC directly to the MBR, a sharp increase in removal efficiency was seen for the seven hydrophilic and biologically persistent trace organic contaminants (metronidazole, fenoprop, ketoprofen, naproxen, diclofenac, carbamazepine and pentachlorophenol), which had previously been removed at low levels by MBR- only treatment (Figure 2). 
In batch adsorption tests conducted following the procedure described in Li et al. [20], the adsorption of the seven problematic hydrophilic compounds $(\log D<3.2)$ on activated sludge (without PAC) ranged from 100 to $900 \mathrm{ng}$ per $\mathrm{g}$ of MLSS, while that on PAC ranged from 40 to $250 \mathrm{mg}$ per $\mathrm{g}$ of PAC (data not shown). The rapid increase in removal efficiency of the aforementioned seven biologically persistent hydrophilic compounds after PAC addition to MBR reconfirmed that the biological sludge only had a limited capacity to adsorb these compounds and that PAC-amended sludge provided a better surface to adsorb and remove more of them (Figure 2). Significant adsorption of the hydrophilic compounds onto PAC-amended sludge may be explained by the fact that other mechanisms apart from hydrophobic interaction can play a role in the adsorption of target compounds onto activated carbon [35-38].

In this study, the removal efficiency of some compounds (metronidazole, fenoprop, naproxen and diclofenac) dropped significantly within 11 days of operation with a PAC concentration of $0.1 \mathrm{~g} / \mathrm{L}$ (Figure 3). Observation of trace organic contaminant removal by the PAC - MBR system for a further 20 days revealed no increase in the removal efficiency of the biologically persistent and hydrophilic trace organic contaminants. Thus the increase in removal efficiency of the hydrophilic and biologically persistent compounds under a PAC concentration of $0.1 \mathrm{~g} / \mathrm{L}$ was only temporary (Figure 3), suggesting that "biologically activated carbon" wherein adsorption, biodegradation and PAC regeneration may occur simultaneously [12, 39] was not fully established. This may be attributed to two likely reasons: i) under competition with other organic compounds in the synthetic wastewater, only a small fraction of the PAC added to the MBR can be effectively utilised for adsorption of trace organic contaminants [20, 21], ii) pore blockage by bulk organic matter including products of microbial degradation and dead microbial cells reduces the adsorption capacity of target compounds on PAC [40, 41].

FIGURE 3 


\subsubsection{Removal using a PAC concentration of $0.5 \mathrm{~g} / \mathrm{L}$}

As opposed to only temporary improvement described in section 3.4.2.1, achievement of a more stable removal performance was clearly an important objective. For further assessment of the consistency of the improvement of the removal performance through PAC addition, 36 days after the first addition of PAC, PAC was added again to obtain a PAC concentration of $0.5 \mathrm{~g} / \mathrm{L}$ in the MBR. It is noted that the 15 compounds (nine hydrophobic and six hydrophilic compounds) which had been consistently well removed by PAC - MBR at a PAC concentration of $0.1 \mathrm{~g} / \mathrm{L}$ (Figure 3), continued to be removed very effectively at the elevated PAC concentration. Therefore, further discussion will focus on seven problematic compounds, namely, metronidazole, fenoprop, ketoprofen, naproxen, diclofenac, carbamazepine and pentachlorophenol, which showed particular persistence during long-term operation under a PAC concentration of $0.1 \mathrm{~g} / \mathrm{L}$ (Figure 3).

Similar to the case of $0.1 \mathrm{~g}$ PAC/ L, raising the PAC concentration in the MBR to $0.5 \mathrm{~g} / \mathrm{L}$, resulted in an immediate improvement in the removal of all seven of these persistent compounds but the removal efficiency subsequently dropped gradually over time. The profile of removal efficiency followed different trends depending on the particular compound and PAC concentration (Figure 4). Fenoprop and diclofenac showed extraordinary persistence (Figure 3 and 4). The variation in removal efficiency for different compounds may be attributed to the adsorption affinity of each compound on PAC. Different degrees of affinity of trace organic contaminants toward PAC have been reported in the previous studies [22, 42, 43]. For instance, Westerhoff et al. [43] reported that ibuprofen adsorbed poorly (20\%), while trimethoprim and fluoxetine adsorbed highly (90\%) on PAC. $\mathrm{Yu}$ et al. [42] reported that naproxen and carbamazepine, but not diclofenac, could be effectively removed by PAC adsorption. Of particular relevance to our study, in a PAC-MBR study, Serrano et al. [22] reported that most of the compounds (e.g., carbamazepine, naproxen and diclofenac) could be significantly removed after adding PAC to the MBR; however, the adsorption capacity of PAC eventually became saturated in that study. The order of compounds in terms of 
decreasing removal efficiency was shown to be: ibuprofen > carbamazepine > naproxen > diclofenac [22]. Our results are in good agreement with this observation.

\section{FIGURE 4}

\subsubsection{Removal performance versus loading on PAC}

In contrast with the case of $0.1 \mathrm{~g}$ PAC/L, after approximately one month of the application of $0.5 \mathrm{~g}$ PAC/L, the removal of none of the compounds dropped to the level attained by MBR-only treatment (Figure 4). More specifically, even one month after raising the PAC concentration in the MBR to $0.5 \mathrm{~g} / \mathrm{L}$, the removal of ketoprofen, naproxen, carbamazepine and pentachlorophenol was sustained at $90 \%$, while fenoprop, diclofenac and metronidazole were removed with an efficiency of 60 to $70 \%$. Our observation regarding the effect of PAC dose is in line with that of Li et al. [20] who observed that when the PAC concentration in an MBR was raised to $1.0 \mathrm{~g} / \mathrm{L}$ from $0.1 \mathrm{~g} / \mathrm{L}$, the removal efficiency of carbamazepine increased to $92 \pm 15 \%$ from negligible removal. However, the more stable removal efficiency of certain compounds at the higher PAC dose $(0.5 \mathrm{~g}$ PAC/L $)$ over one month (Figure 4) appears to reflect the situation that for this dose the PAC adsorption capacity was not exhausted within this period. This can be clarified by Figure 5 which shows that the removal efficiency of fenoprop and diclofenac indeed reduced gradually with operation time even in case of the higher PAC dose, suggesting gradual saturation of the adsorptive capacity of PAC.

\section{FIGURE 5}

For a valid comparison of performance between the two doses of PAC, treated volume per unit weight of PAC needs to be considered. The removal efficiency using the two PAC doses taking into consideration the treated volume per unit weight of PAC $(\mathrm{L} / \mathrm{g})$ was compared in Figure 6 for fenoprop and diclofenac, which showed extraordinary persistence in this study. In fact, up to a PAC usage rate of $120 \mathrm{~L} / \mathrm{g}$ (corresponding to 12 and 48 days of operation at $0.1 \mathrm{~g}$ and $0.5 \mathrm{~g} / \mathrm{L}$ doses, respectively), better (fenoprop) or similar (diclofenac) levels of removal was achieved using a PAC concentration of $0.1 \mathrm{~g} / \mathrm{L}$. It is note-worthy that immediately after adding into MBR, PAC 
can adsorb a wide range of bulk organic matter including products of microbial degradation and dead microbial cells [44]. Our results suggest that, up to a certain level of loading on PAC, in order to minimize loss of adsorptive sites due to adsorption of bulk organics and consequently reduce overall PAC consumption, the application of relatively frequent but smaller dosage of PAC may be recommendable.

\section{FIGURE 6}

In addition to the aqueous phase removal, the fate of trace organic compounds adsorbed on MLSS is also important. At the end of this study, the mass of the compounds adsorbed onto per unit mass of the PAC-added sludge was estimated (Supplementary Data Figure S6). Interestingly, the concentration of nine hydrophobic compounds varied greatly (110 - 7390 ng/gMLSS). Except for bisphenol A, 17- $\alpha$-ethynylestradiol, 4-tert-octyl phenol and triclosan, all other hydrophobic compounds were present at a concentration of less than $1000 \mathrm{ng} / \mathrm{g}$ MLSS, possibly due to faster biodegradation. On the other hand, despite being significantly hydrophilic, carbamazepine and pentachlorophenol were present at concentrations of 7390 and $5700 \mathrm{ng} / \mathrm{g}$ MLSS, respectively, underscoring their biological persistence. This indicated that although a relatively stable aqueous phase removal of resistant trace organic contaminants may be accomplished by PAC addition to MBR, the sludge at the time of withdrawal may contain significant amounts of undegraded compounds. This aspect warrants further investigation; however, it is beyond the scope of the current study.

\section{Conclusions}

Data presented in this study systematically confirm the following aspects specifically from the point view of trace organic contaminant removal: i) PAC-amended sludge provides a better surface to adsorb more trace organic contaminants and achieve better aqueous phase removal; ii) periodic withdrawal and replenishment of PAC is required for stable removal, and in this case, frequent and 
smaller-dose PAC addition is preferable; and iii) the extent of biodegradation (transformation) following adsorption onto PAC-sludge is compound-specific.

Of the 22 compounds investigated in this study, fenoprop and diclofenac showed extraordinary persistence to MBR-only treatment, and their removal efficiency also decreased faster (down to $<10 \%$ level in one month) after the small-dose $(0.1 \mathrm{~g} / \mathrm{L})$ addition of PAC. Although effective aqueous phase removal of some other persistent compounds such as carbamazepine and pentachlorophenol for longer periods after PAC dosing was observed, adsorption onto PAC-added sludge appeared to play a significant role. Stable performance for longer periods was observed under an elevated PAC concentration of $0.5 \mathrm{~g} / \mathrm{L}$. However, comparison of the removal efficiency while taking into consideration the treated volume per unit weight of PAC $(\mathrm{L} / \mathrm{g})$ confirmed the suitability of smaller-dose PAC addition up to a certain level of loading on PAC. This study lays the foundation for future studies on the assessment of the frequency of withdrawal/replenishment of PAC and thorough monitoring of the fate of trace organic contaminants in the aqueous phase and in sludge in a PAC-added MBR.

\section{Acknowledgement}

A postgraduate scholarship to Luong Nguyen from the University of Wollongong, Australia and the Thanh Hoa provincial government (Vietnam) is greatly appreciated. Mitsubishi Rayon Engineering, Japan, Activated Carbon Technologies Pty Ltd, Australia and Australian Nuclear Science and Technology Organisation (ANSTO) are thanked for the provision to membrane module, PAC samples, and analysis of PAC properties, respectively.

\section{References}

[1] Kolpin, DW, Furlong, ET, Meyer, MT, Thurman, EM, Zaugg, SD, Barber, LB, Buxton, HT. Pharmaceuticals, Hormones, and Other Organic Wastewater Contaminants in U.S. Streams, 1999 2000: A National Reconnaissance. Environ Sci Technol 2002; 36: 1202-11.

[2] Hai, FI, Nghiem, LD, Khan, SJ, Price, WE, Yamamoto, K. "Wastewater reuse: Removal of Emerging Trace Organic Contaminants" in Membrane Biological reactors, (eds. Hai, FI, 
Yamamoto, K. and Lee, C-H), IWA publishing, UK, 2013 (ISBN: 9781780400655; accepted, Oct 2012).

[3] Melin, T, Jefferson, B, Bixio, D, Thoeye, C, De Wilde, W, De Koning, J, van der Graaf, J, Wintgens, T. Membrane bioreactor technology for wastewater treatment and reuse. Desalination 2006; 187: 271-82.

[4] Clara, M, Strenn, B, Gans, O, Martinez, E, Kreuzinger, N, Kroiss, H. Removal of selected pharmaceuticals, fragrances and endocrine disrupting compounds in a membrane bioreactor and conventional wastewater treatment plants. Water Res 2005; 39: 4797-807.

[5] Joss, A, Keller, E, Alder, AC, Göbel, A, McArdell, CS, Ternes, T, Siegrist, H. Removal of pharmaceuticals and fragrances in biological wastewater treatment. Water Res 2005; 39: 3139-52.

[6] Tadkaew, N, Hai, FI, McDonald, JA, Khan, SJ, Nghiem, LD. Removal of trace organics by MBR treatment: The role of molecular properties. Water Res 2011; 45: 2439-51.

[7] Chen, J, Huang, X, Lee, D. Bisphenol A removal by a membrane bioreactor. Process Biochem 2008; 43: 451-6.

[8] Reif, R, Suairez, S, Omil, F, Lema, JM. Fate of pharmaceuticals and cosmetic ingredients during the operation of a MBR treating sewage. Desalination 2008; 221: 511-7.

[9] Tadkaew, N, Sivakumar, M, Khan, SJ, McDonald, JA, Nghiem, LD. Effect of mixed liquor pH on the removal of trace organic contaminants in a membrane bioreactor. Bioresource Technol 2010; 101: 1494-500.

[10] Hai, FI, Tessmer, K, Nguyen, LN, Kang, J, Price, WE, Nghiem, LD. Removal of micropollutants by membrane bioreactor under temperature variation. J Membrane Sci 2011; 383: 144-51.

[11] Joss, A, Zabczynski, S, Göbel, A, Hoffmann, B, Löffler, D, McArdell, CS, Ternes, TA, Thomsen, A, Siegrist, H. Biological degradation of pharmaceuticals in municipal wastewater treatment: Proposing a classification scheme. Water Res 2006; 40: 1686-96.

[12] Hai, FI, Yamamoto, K, Nakajima, F, Fukushi, K. Removal of structurally different dyes in submerged membrane fungi reactor - Biosorption/PAC-adsorption, membrane retention and biodegradation. J Membrane Sci 2008; 325: 395-403.

[13] Guo, W, Vigneswaran, S, Ngo, H-H, Xing, W, Goteti, P. Comparison of the performance of submerged membrane bioreactor (SMBR) and submerged membrane adsorption bioreactor (SMABR). Bioresource Technol 2008; 99: 1012-7.

[14] Gai, X-J, Kim, H-S. The role of powdered activated carbon in enhancing the performance of membrane systems for water treatment. Desalination 2008; 225: 288-300.

[15] Remy, M, Potier, V, Temmink, H, Rulkens, W. Why low powdered activated carbon addition reduces membrane fouling in MBRs. Water Res 2010; 44: 861-7. 
[16] Chavalit, R, Numchai, N. Performance of Biological Powdered Activated Carbon-Membrane Bioreactor (BPAC-MBR) for old-landfill leachate treatment. Int J Environ Waste Manage 2009; 4: 271-81.

[17] Lesage, N, Sperandio, M, Cabassud, C. Study of a hybrid process: Adsorption on activated carbon/membrane bioreactor for the treatment of an industrial wastewater. Chem Eng Process: Process Intensification 2007; 47: 303-7.

[18] Munz, G, Gori, R, Mori, G, Lubello, C. Powdered activated carbon and membrane bioreactors (MBR-PAC) for tannery wastewater treatment: long term effect on biological and filtration process performances. Desalination 2007; 207: 349-60.

[19] Satyawali, Y, Balakrishnan, M. Performance enhancement with powdered activated carbon (PAC) addition in a membrane bioreactor (MBR) treating distillery effluent. J Hazard Mater 2009; 170: 457-65.

[20] Li, X, Hai, FI, Nghiem, LD. Simultaneous activated carbon adsorption within a membrane bioreactor for an enhanced micropollutant removal. Bioresource Technol 2011; 102: 5319-24.

[21] Zhang, L, Q., Urase, T, Feng, L. Removal of carbamazepine in an enhanced membrane bioreactor with small dose addition of powdered activated carbon. In: Wang, X, Chen, R, editors. Advances in Chemical Technologies for Water and Wastewater Treatment, Shanxi: Shaanxi Sci \& Tech Publ House; 2008, p. 199-205.

[22] Serrano, D, Suárez, S, Lema, JM, Omil, F. Removal of persistent pharmaceutical micropollutants from sewage by addition of PAC in a sequential membrane bioreactor. Water Res 2011; 45: 5323-33.

[23] Yang, W, Paetkau, M, Cicek, N. Improving the performance of membrane bioreactors by powdered activated carbon dosing with cost considerations. Water Sci Technol 2010; 62: 172-9.

[24] Lipp, P, Groay, H-J, Tiehm, A. Improved elimination of organic micropollutants by a process combination of membrane bioreactor (MBR) and powdered activated carbon (PAC). Desalination Water T 2012; 42: 65-72.

[25] Nguyen, LN, Hai, FI, Kang, J, Price, WE, Nghiem, LD. Removal of trace organic contaminants by a membrane bioreactor - granular activated carbon (MBR-GAC) system. Bioresource Technol 2012; 113: 169-73.

[26] Eaton, AD, Clescerl, LS, Rice, EW, Greenberg, AE. Standard Methods for Examination of Water \& Wastewater, in, American Public Health Association, 2005.

[27] Şeker, Ş, Beyenal, H, Tanyolaç, A. The effects of biofilm thickness on biofilm density and substrate consumption rate in a differential fluidizied bed biofilm reactor (DFBBR). J Biotechnol 1995; 41: 39-47. 
[28] Delai Sun, D, Loong Khor, S, Teck Hay, C, Leckie, JO. Impact of prolonged sludge retention time on the performance of a submerged membrane bioreactor. Desalination 2007; 208: 101-12.

[29] Li, Y-Z, He, Y-L, Liu, Y-H, Yang, S-C, Zhang, G-J. Comparison of the filtration characteristics between biological powdered activated carbon sludge and activated sludge in submerged membrane bioreactors. Desalination 2005; 174: 305-14.

[30] Ravindran, V, Tsai, H-H, Williams, MD, Pirbazari, M. Hybrid membrane bioreactor technology for small water treatment utilities: Process evaluation and primordial considerations. J Membrane Sci 2009; 344: 39-54.

[31] Ying, Z, Ping, G. Effect of powdered activated carbon dosage on retarding membrane fouling in MBR. Sep Purif Technol 2006; 52: 154-60.

[32] Sagbo, O, Sun, Y, Hao, A, Gu, P. Effect of PAC addition on MBR process for drinking water treatment. Sep Purif Technol 2008; 58: 320-7.

[33] Urase, T, Kagawa, C, Kikuta, T. Factors affecting removal of pharmaceutical substances and estrogens in membrane separation bioreactors. Desalination 2005; 178: 107-13.

[34] Alturki, AA, Tadkaew, N, McDonald, JA, Khan, SJ, Price, WE, Nghiem, LD. Combining MBR and NF/RO membrane filtration for the removal of trace organics in indirect potable water reuse applications. J Membrane Sci 2010; 365: 206-15.

[35] de Ridder, DJ, Villacorte, L, Verliefde, ARD, Verberk, JQJC, Heijman, SGJ, Amy, GL, van Dijk, JC. Modeling equilibrium adsorption of organic micropollutants onto activated carbon. Water Res 2010; 44: 3077-86.

[36] Dickenson, ERV, Drewes, JE. Quantitative structure property relationships for the adsorption of pharmaceuticals onto activated carbon. Water Sci Technol 2010; 62: 2270-6.

[37] Hernández-Leal, L, Temmink, H, Zeeman, G, Buisman, CJN. Removal of micropollutants from aerobically treated grey water via ozone and activated carbon. Water Res 2011; 45: 2887-96.

[38] Vieno, NM, Härkki, H, Tuhkanen, T, Kronberg, L. Occurrence of Pharmaceuticals in River Water and Their Elimination in a Pilot-Scale Drinking Water Treatment Plant. Environ Sci Technol 2007; 41: 5077-84.

[39] Dosoretz, CG, Böddeker, KW. Removal of trace organics from water using a pumped bedmembrane bioreactor with powdered activated carbon. J Membrane Sci 2004; 239: 81-90.

[40] Snyder, SA, Adham, S, Redding, AM, Cannon, FS, DeCarolis, J, Oppenheimer, J, Wert, EC, Yoon, Y. Role of membranes and activated carbon in the removal of endocrine disruptors and pharmaceuticals. Desalination 2007; 202: 156-81.

[41] Fukuhara, T, Iwasaki, S, Kawashima, M, Shinohara, O, Abe, I. Adsorbability of estrone and 17- $\beta$-estradiol in water onto activated carbon. Water Res 2006; 40: 241-8. 
[42] Yu, Z, Peldszus, S, Huck, PM. Adsorption characteristics of selected pharmaceuticals and an endocrine disrupting compound--Naproxen, carbamazepine and nonylphenol--on activated carbon. Water Res 2008; 42: 2873-82.

[43] Westerhoff, P, Yoon, Y, Snyder, S, Wert, E. Fate of Endocrine-Disruptor, Pharmaceutical, and Personal Care Product Chemicals during Simulated Drinking Water Treatment Processes. Environ Sci Technol 2005; 39: 6649-63.

[44] Aun Ng, C, Sun, D, Fane, AG. Operation of Membrane Bioreactor with Powdered Activated Carbon Addition. Sep Purif Technol 2006; 41: 1447-66. 


\section{LIST OF TABLES}

Table 1: Physicochemical properties of the selected trace organics

Table 2: Characteristics of the PAC-1000 .

Table 3: Stable operating conditions and biological performance during operation of MBR and PAC - MBR systems. 
Table 4: Physicochemical properties of the selected trace organics *

\begin{tabular}{|c|c|c|c|c|c|c|c|c|}
\hline Category & Compound & CAS number & $\begin{array}{l}\text { Structural } \\
\text { formula }\end{array}$ & $\begin{array}{c}\text { Molecul } \\
\text { ar } \\
\text { weight } \\
(\mathrm{g} / \mathrm{mol})\end{array}$ & $\begin{array}{c}\log D \\
\underset{\mathrm{a}}{(\mathrm{pH} 7)}\end{array}$ & $\begin{array}{c}\text { Vapor } \\
\text { pressure } \\
(\mathrm{mm} \mathrm{Hg}) \text {, } \\
\text { at } 25^{\circ} \mathrm{C}^{\mathrm{a}}\end{array}$ & $\begin{array}{c}\text { Henry's } \\
\text { law } \\
\text { constant } \\
\left(\text { atm* }{ }^{3} /\right. \\
\text { mole) at } \\
25^{0} \mathrm{C}^{\mathrm{b}}\end{array}$ & $\begin{array}{l}\text { Limit of } \\
\text { detection } \\
(\mathrm{ng} / \mathrm{L})^{\mathrm{c}}\end{array}$ \\
\hline \multirow{11}{*}{ 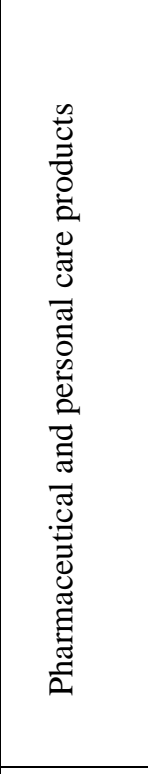 } & Ibuprofen & $5687-27-1$ & $\mathrm{C}_{13} \mathrm{H}_{18} \mathrm{O}_{2}$ & 206.28 & 0.94 & $1.39 \mathrm{E}-4$ & $1.50 \mathrm{E}-07$ & 20 \\
\hline & Acetaminophen & $103-90-2$ & $\mathrm{C}_{8} \mathrm{H}_{9} \mathrm{NO}_{2}$ & 151.16 & 0.47 & $1.43 \mathrm{E}-6$ & $6.42 \mathrm{E}-13$ & 20 \\
\hline & Naproxen & 22204-53-1 & $\mathrm{C}_{14} \mathrm{H}_{14} \mathrm{O}_{3}$ & 230.26 & 0.73 & $3.01 \mathrm{E}-7$ & $3.39 \mathrm{E}-10$ & 1 \\
\hline & Ketoprofen & $22071-15-4$ & $\mathrm{C}_{16} \mathrm{H}_{14} \mathrm{O}_{3}$ & 254.28 & 0.19 & $3.32 \mathrm{E}-8$ & $2.12 \mathrm{E}-11$ & 20 \\
\hline & Diclofenac & $15307-86-5$ & $\mathrm{C}_{14} \mathrm{H}_{11} \mathrm{Cl}_{2} \mathrm{NO}_{2}$ & 296.15 & 1.77 & $1.59 \mathrm{E}-7$ & 4.73E-12 & 5 \\
\hline & Primidone & $125-33-7$ & $\mathrm{C}_{12} \mathrm{H}_{14} \mathrm{~N}_{2} \mathrm{O}_{2}$ & 218.25 & 0.83 & $6.08 \mathrm{E}-11$ & $1.94 \mathrm{E}-10$ & 10 \\
\hline & Carbamazepine & $298-46-4$ & $\mathrm{C}_{15} \mathrm{H}_{12} \mathrm{~N}_{2} \mathrm{O}$ & 236.27 & 1.89 & $5.78 \mathrm{E}-7$ & $1.08 \mathrm{E}-10$ & 10 \\
\hline & Salicylic acid & $69-72-7$ & $\mathrm{C}_{7} \mathrm{H}_{6} \mathrm{O}_{3}$ & 138.12 & -1.13 & $4.45 \mathrm{E}-5$ & 7.34E-09 & 1 \\
\hline & Metronidazole & $443-48-1$ & $\mathrm{C}_{6} \mathrm{H}_{9} \mathrm{~N}_{3} \mathrm{O}_{3}$ & 171.15 & -0.14 & $2.67 \mathrm{E}-7$ & $1.69 \mathrm{E}-11$ & 20 \\
\hline & Gemifibrozil & 25812-30-0 & $\mathrm{C}_{15} \mathrm{H}_{22} \mathrm{O}_{3}$ & 250.33 & 2.07 & $6.13 \mathrm{E}-7$ & na & 1 \\
\hline & Triclosan & $3380-34-5$ & $\mathrm{C}_{12} \mathrm{H}_{7} \mathrm{Cl}_{3} \mathrm{O}_{2}$ & 289.54 & 5.28 & $3.36 \mathrm{E}-5$ & 4.99E-09 & 1 \\
\hline \multirow{2}{*}{ 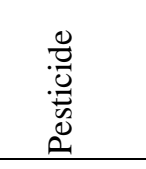 } & Fenoprop & $93-72-1$ & $\mathrm{C}_{9} \mathrm{H}_{7} \mathrm{Cl}_{3} \mathrm{O}_{3}$ & 269.51 & -0.13 & $2.13 \mathrm{E}-6$ & $9.06 \mathrm{E}-09$ & 20 \\
\hline & $\begin{array}{c}\text { Pentachloro- } \\
\text { phenol }\end{array}$ & $87-86-5$ & $\mathrm{C}_{6} \mathrm{HCl}_{5} \mathrm{O}$ & 266.34 & 2.58 & $3.49 \mathrm{E}-4$ & $2.45 \mathrm{E}-08$ & 1 \\
\hline \multirow{4}{*}{ 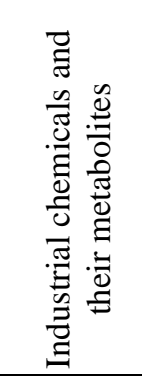 } & $\begin{array}{c}\text { 4-tert- } \\
\text { butylphenol }\end{array}$ & $98-54-4$ & $\mathrm{C}_{10} \mathrm{H}_{14} \mathrm{O}$ & 150.22 & 3.40 & 0.0361 & $1.19 \mathrm{E}-06$ & 1 \\
\hline & $\begin{array}{c}\text { 4-tert- } \\
\text { octylphenol } \\
\end{array}$ & $140-66-9$ & $\mathrm{C}_{14} \mathrm{H}_{22} \mathrm{O}$ & 206.32 & 5.18 & $1.98 \mathrm{E}-3$ & 6.89E-06 & 1 \\
\hline & 4-n-nonylphenol & $104-40-5$ & $\mathrm{C}_{15} \mathrm{H}_{24} \mathrm{O}$ & 220.35 & 6.14 & $8.53 \mathrm{E}-5$ & $1.10 \mathrm{E}-06$ & 10 \\
\hline & Bisphenol A & $80-05-7$ & $\mathrm{C}_{15} \mathrm{H}_{16} \mathrm{O}_{2}$ & 228.29 & 3.64 & $5.34 \mathrm{E}-7$ & $1.00 \mathrm{E}-11$ & 1 \\
\hline \multirow{5}{*}{ 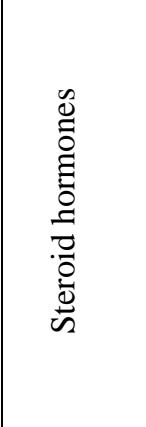 } & Estrone & $53-16-7$ & $\mathrm{C}_{18} \mathrm{H}_{22} \mathrm{O}_{2}$ & 270.37 & 3.62 & $1.54 \mathrm{E}-8$ & $3.80 \mathrm{E}-10$ & 5 \\
\hline & $17-\beta$-estradiol & $50-28-2$ & $\mathrm{C}_{18} \mathrm{H}_{24} \mathrm{O}_{2}$ & 272.38 & 4.15 & $9.82 \mathrm{E}-9$ & $3.64 \mathrm{E}-11$ & 5 \\
\hline & $\begin{array}{c}17-\beta \text {-estradiol - } \\
\text { acetate }\end{array}$ & $1743-60-8$ & $\mathrm{C}_{20} \mathrm{H}_{26} \mathrm{O}_{3}$ & 314.42 & 5.11 & $9.88 \mathrm{E}-9$ & na & 5 \\
\hline & $\begin{array}{c}17-\alpha \\
\text { ethinylestradiol }\end{array}$ & $57-63-6$ & $\mathrm{C}_{20} \mathrm{H}_{24} \mathrm{O}_{2}$ & 269.40 & 4.11 & $3.74 \mathrm{E}-9$ & 7.94E-12 & 10 \\
\hline & Estriol & $50-27-1$ & $\mathrm{C}_{18} \mathrm{H}_{24} \mathrm{O}_{3}$ & 288.38 & 2.53 & $1.34 \mathrm{E}-9$ & $1.33 \mathrm{E}-12$ & 10 \\
\hline
\end{tabular}

\footnotetext{
${ }^{a}$ Source: SciFinder database https://scifinder.cas.org/scifinder/view/scifinder/scifinderExplore.jsf

${ }^{\mathrm{b}}$ Source: http://chem.sis.nlm.nih.gov/chemidplus/

${ }^{\mathrm{c}}$ Limit of detection was defined as the concentration of an analyte giving a signal to noise $(\mathrm{S} / \mathrm{N})$ ratio greater than 3 . The limit of reporting was determined using an $\mathrm{S} / \mathrm{N}$ ration of greater than 10 .

na: data not available

* Other relevant properties are listed in Supplementary Data Table S1
} 
Table 2: Characteristics of the PAC-1000a

\begin{tabular}{|c|c|}
\hline Parameters & Values \\
\hline Apparent density $(\mathrm{g} / \mathrm{mL})^{\mathrm{b}}$ & $0.35-0.45$ \\
\hline $\begin{array}{l}\text { Specific surface area (MultiPoint BET } \\
\left.\qquad \mathrm{m}^{2} / \mathrm{g}\right)^{\mathrm{c}}\end{array}$ & 1355 \\
\hline Ash content $(\%)^{\mathrm{b}}$ & 14 \\
\hline Iodine number $\left(\mathrm{mg} / \mathrm{g} \text { of } \mathrm{I}_{2}\right)^{\mathrm{b}}$ & $>1000$ \\
\hline Particle size ${ }^{b}$ & $15-30 \mu \mathrm{m}$ \\
\hline Pore volume $(\mathrm{mL} / \mathrm{g})^{\mathrm{c}}$ & 0.228 \\
\hline Pore diameter $(\mathrm{nm})^{\mathrm{c}}$ & 3.139 \\
\hline
\end{tabular}

${ }^{a}$ PAC-1000 was supplied by Activated Carbon Technologies Pty Ltd, Australia.

${ }^{\mathrm{b}}$ Data from Activated Carbon Technologies Pty Ltd, Australia.

${ }^{\mathrm{c}}$ Data obtained from a nitrogen adsorption/desorption measurement using an Autosorb iQ.

The measurement was conducted at the Australian Nuclear Science and Technology Organisation. Pore volume and pore diameter were calculated based on the Barret-JoynerHalenda method. 
Table 3: Stable operating conditions and biological performance during operation of MBR and PAC - MBR systems.

\begin{tabular}{|c|c|c|c|c|c|c|c|c|}
\hline Process & $\begin{array}{c}\text { Temperature } \\
\left({ }^{\circ} \mathrm{C}\right)^{\mathrm{a}}\end{array}$ & $\begin{array}{c}\text { DO } \\
\text { concentration } \\
(\mathrm{mg} / \mathrm{L})^{\mathrm{a}}\end{array}$ & $\begin{array}{l}\text { HRT, } \\
(\mathrm{hr})^{\mathrm{a}}\end{array}$ & $\mathrm{pH}^{\mathrm{b}}$ & $\begin{array}{l}\text { MLVSS/ } \\
\text { MLSS } \\
\text { ratio }^{b}\end{array}$ & $\begin{array}{c}\text { Supernatant } \\
\text { turbidity } \\
\text { (NTU) }^{\mathrm{b}}\end{array}$ & $\begin{array}{c}\text { SVI } \\
(\mathrm{mL} / \\
\mathrm{g} \mathrm{MLSS}^{\mathrm{b}}\end{array}$ & $\begin{array}{c}\text { SOUR } \\
\left(\mathrm{mg} \mathrm{O}_{2} /\right. \\
\left.\mathrm{h}^{*} \mathrm{~g} \text { MLSS }\right)^{\mathrm{b}}\end{array}$ \\
\hline MBR-only & $22 \pm 0.1$ & $4 \pm 1$ & 24 & $\begin{array}{l}7.4 \pm 0.2 \\
(n=21)\end{array}$ & $\begin{array}{c}0.89 \pm 0.03 \\
(n=40)\end{array}$ & $\begin{array}{c}7 \pm 4 \\
(n=58)\end{array}$ & $\begin{array}{c}162 \pm 29 \\
(n=10)\end{array}$ & $\begin{array}{c}14 \pm 3 \\
(n=10)\end{array}$ \\
\hline $\begin{array}{c}\text { MBR-PAC } \\
(0.1 \mathrm{~g} / \mathrm{L})\end{array}$ & $22 \pm 0.1$ & $4 \pm 1$ & 24 & $\begin{array}{c}7.6 \pm 0.1 \\
(n=5)\end{array}$ & $\begin{array}{c}0.82 \pm 0.09 \\
(n=7)\end{array}$ & $\begin{array}{c}4 \pm 1 \\
(n=4)\end{array}$ & $\begin{array}{l}153 \pm 8 \\
(n=4)\end{array}$ & $\begin{array}{l}23 \pm 2 \\
(\mathrm{n}=4)\end{array}$ \\
\hline $\begin{array}{c}\text { MBR-PAC } \\
(0.5 \mathrm{~g} / \mathrm{L})\end{array}$ & $22 \pm 0.1$ & $4 \pm 1$ & 24 & $\begin{array}{c}7.3 \pm 0.3 \\
(n=5)\end{array}$ & $\begin{array}{c}0.86 \pm 0.17 \\
(n=12)\end{array}$ & $\begin{array}{c}4 \pm 2 \\
(n=6)\end{array}$ & $\begin{array}{l}142 \pm 4 \\
(n=6)\end{array}$ & $\begin{array}{l}21 \pm 8 \\
(n=6)\end{array}$ \\
\hline
\end{tabular}

${ }^{\mathrm{a}}$ controlled; ${ }^{\mathrm{b}}$ average \pm standard deviation 


\section{LIST OF FIGURES}

Figure 1: (a) TOC and (b) TN concentration profile influent and effluent in MBR and PAC - MBR system throughout the operating period. "I" indicates the period when the concentration of constituents in synthetic wastewater was temporarily maintained at elevated levels (double). "T" indicates the point of trace organic contaminants addition. " $\mathrm{P}_{1}$ " and " $\mathrm{P}_{2}$ " indicate the points of PAC addition to achieve final PAC concentrations of $0.1 \mathrm{~g} / \mathrm{L}$ and $0.5 \mathrm{~g} / \mathrm{L}$, respectively.

Figure 2: Removal efficiency of trace organic contaminants by MBR-only and PAC - MBR systems (two days after addition of PAC at a concentration of $0.1 \mathrm{~g} / \mathrm{L}$ ), respectively. Error bars represent standard deviation of 40 measurements regularly conducted over MBR-only operation period. Duplicate samples of both influent and effluent were taken once a week for trace organic contaminant analysis throughout the operating period.

Figure 3: Change in the removal of hydrophilic compounds $(\log D<3.2)$ by the PAC - MBR system after addition of PAC at a concentration of $0.1 \mathrm{~g} / \mathrm{L}$. Duplicate samples of both influent and effluent were taken once a week for trace organic contaminant analysis throughout the operating period.

Figure 4: Comparison of level of removal of seven problematic, hydrophilic trace organic contaminants by PAC - MBR system after 31 and 33 days of PAC addition at concentrations of 0.1 $\mathrm{g} / \mathrm{L}$ and $0.5 \mathrm{~g} / \mathrm{L}$, respectively. Error bars represent standard deviation of 40 measurements regularly conducted over MBR-only operation period. Over 95\% removal of all compounds was achieved immediately after PAC addition.

Figure 5: Change in the removal efficiency of three hydrophilic compounds $(\log D<3.2)$ by MBRonly and PAC-MBR. Duplicate samples of both influent and effluent were taken once a week for trace organic contaminant analysis throughout the operating period.

Figure 6: Removal efficiency of fenoprop and diclofenac by PAC - MBR at different loadings on PAC while using PAC concentrations of $0.1 \mathrm{~g} / \mathrm{L}$ and $0.5 \mathrm{~g} / \mathrm{L}$, respectively. 

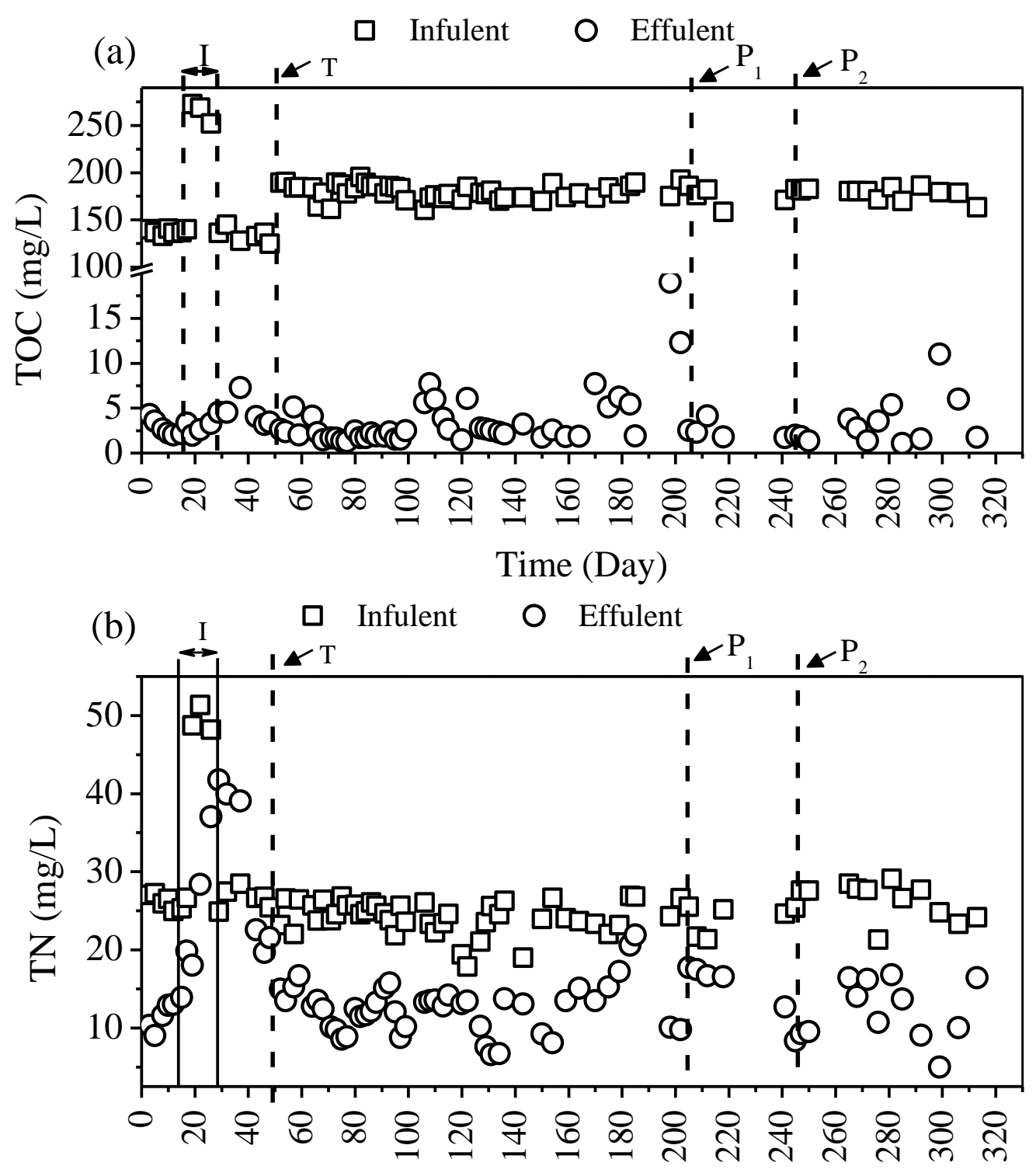

Time (Day)

Figure 1 


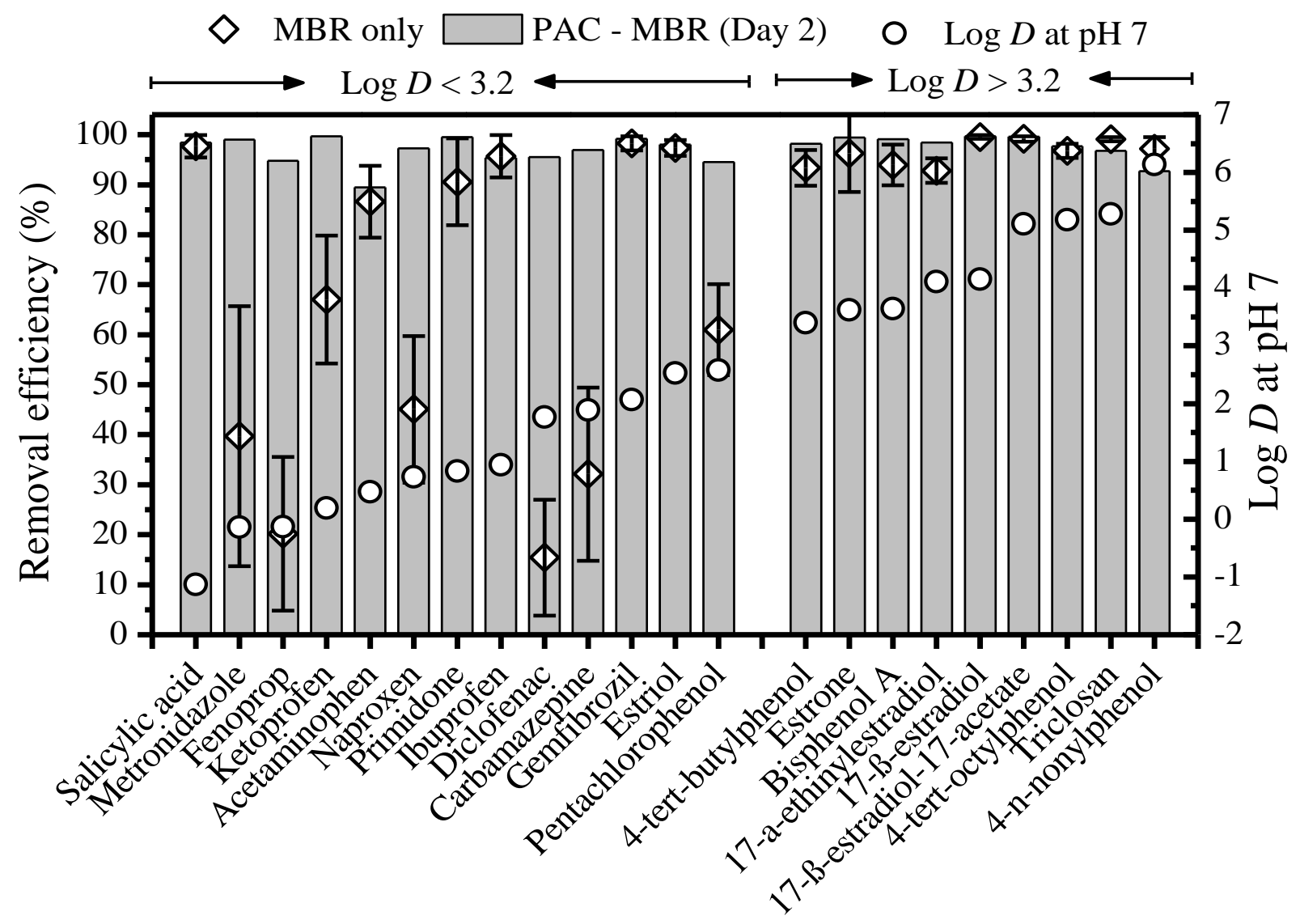

Figure 2 


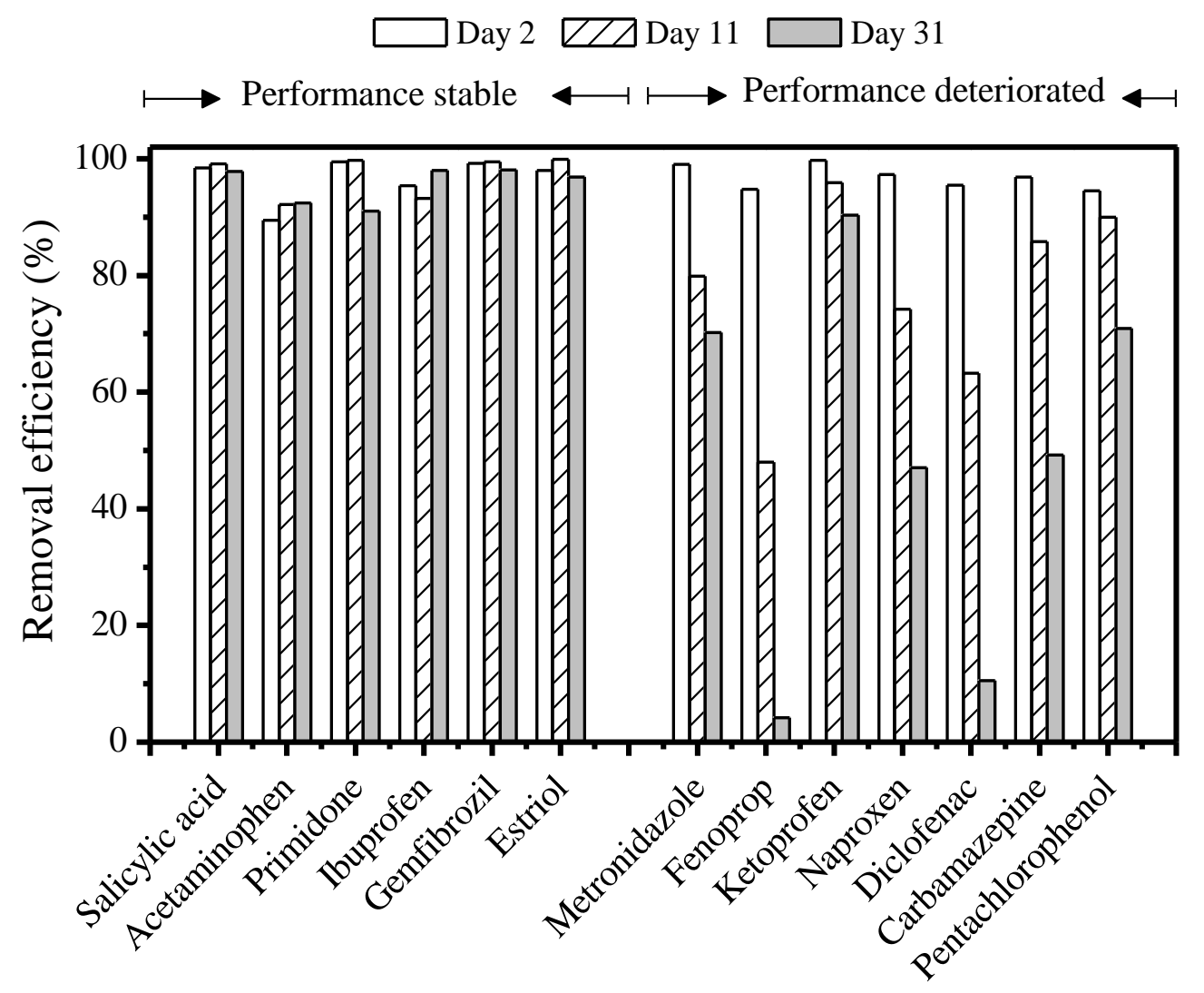

Figure 3 


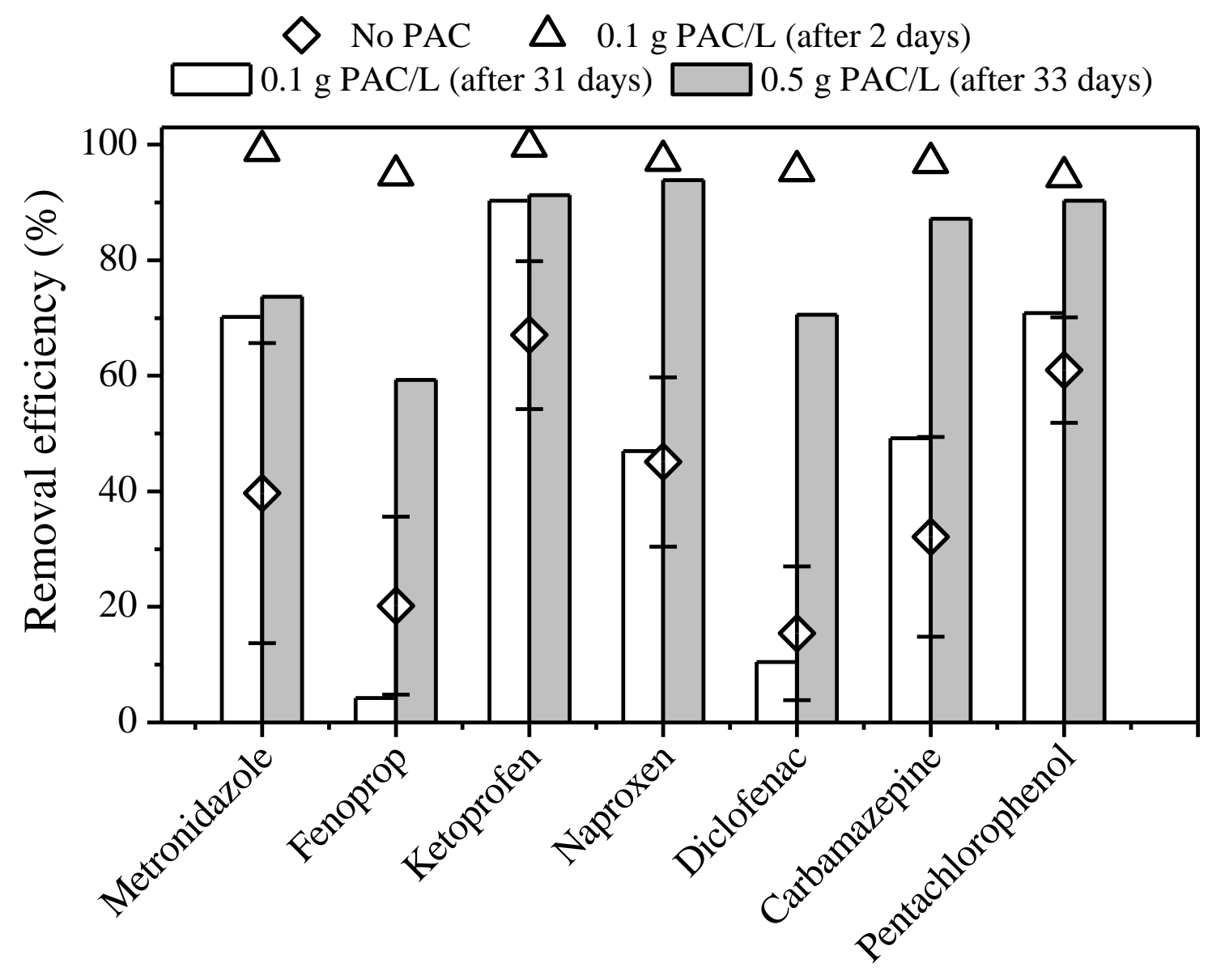

Figure 4 


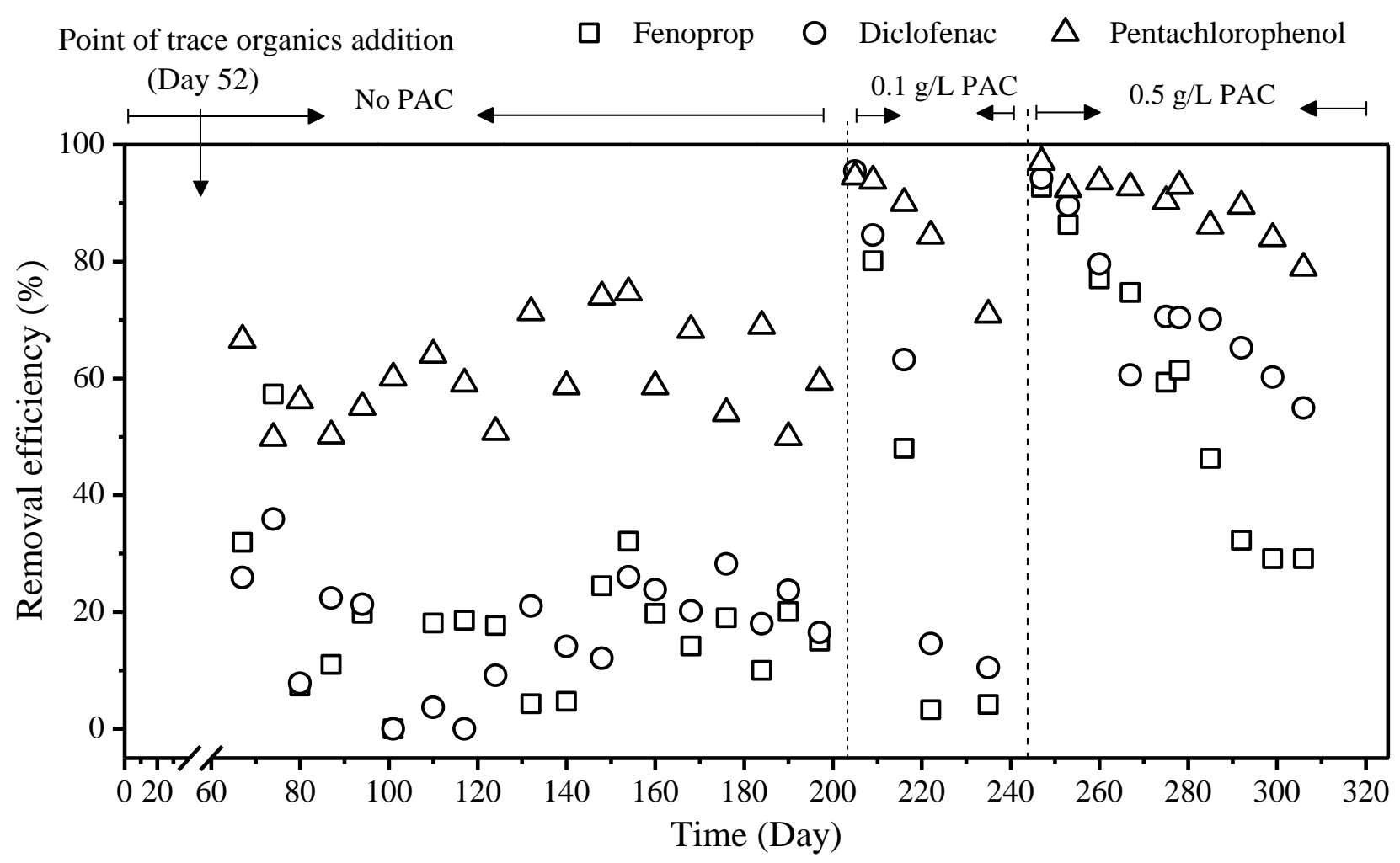

Figure 5 


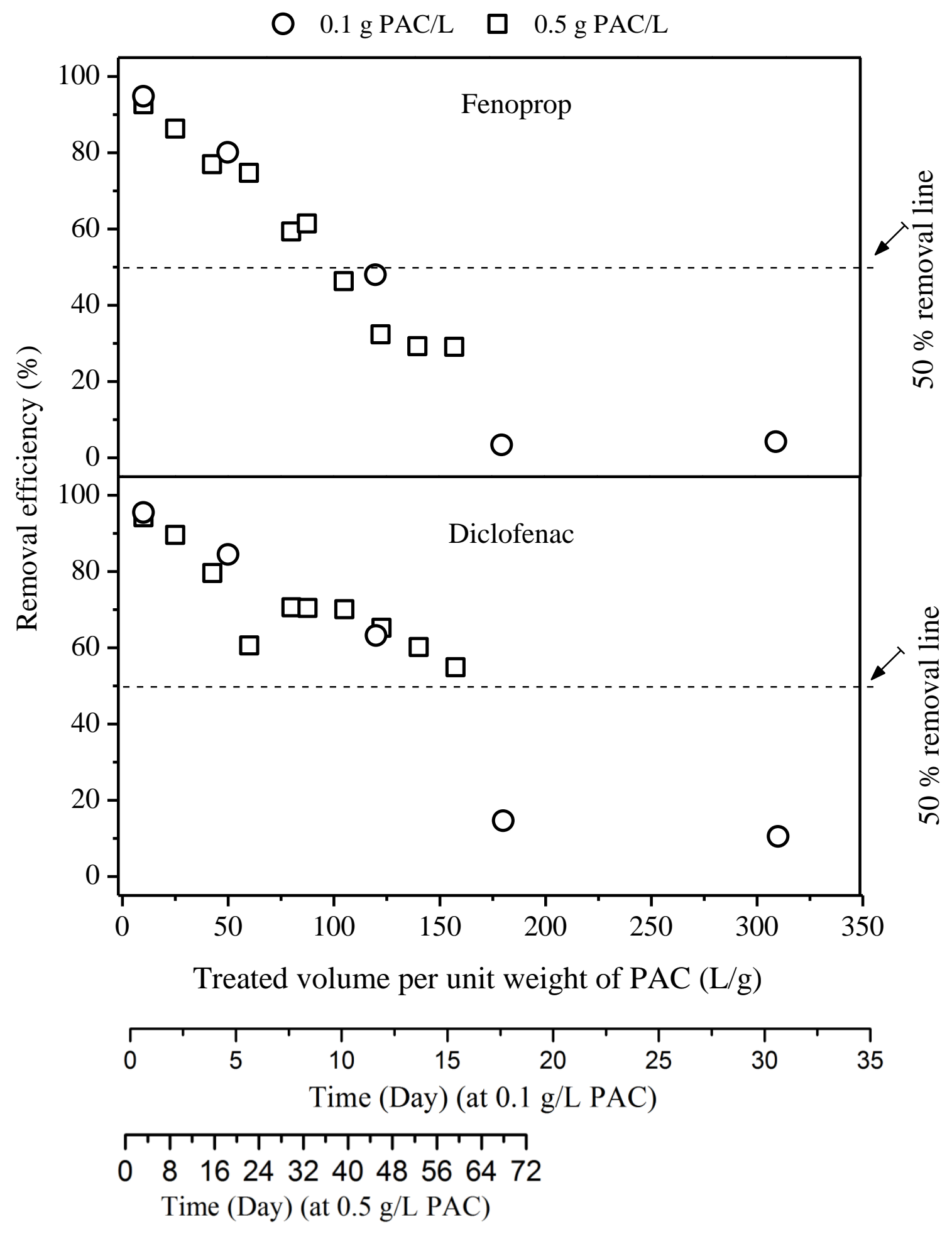

Figure 6 


\section{SUPPLEMENTARY DATA}

\section{Enhancement of removal of trace organic contaminants by powdered activated carbon dosing into membrane bioreactors}

Luong N. Nguyen ${ }^{\mathrm{a}}$, Faisal I. Hai ${ }^{\mathrm{a}}{ }^{\text {, }}$, Long D. Nghiem ${ }^{\mathrm{a}}$, Jinguo Kang ${ }^{\mathrm{a}, \mathrm{b}}$, William E. Price ${ }^{\mathrm{b}}$, Chul Park $^{\mathrm{c}}$ and Kazuo Yamamoto ${ }^{\mathrm{d}}$

${ }^{a}$ Strategic Water Infrastructure Laboratory, School of Civil, Mining and Environmental Engineering, University of Wollongong, Wollongong, NSW 2522, Australia

${ }^{\mathrm{b}}$ Strategic Water Infrastructure Laboratory, School of Chemistry, University of Wollongong, Wollongong, NSW 2522, Australia

${ }^{c}$ Department of Civil and Environmental Engineering, University of Massachusetts, Amherst, MA 01003, United States

${ }^{\mathrm{d}}$ Environmental Science Center, The University of Tokyo, 7-3-1 Hongo, Bunkyo-ku, Tokyo, 113-0033, Japan 
* Corresponding author: Faisal I. Hai, Email: faisal@uow.edu.au, Ph +612 42213054 
Table S1: Physicochemical properties of the selected trace organics.

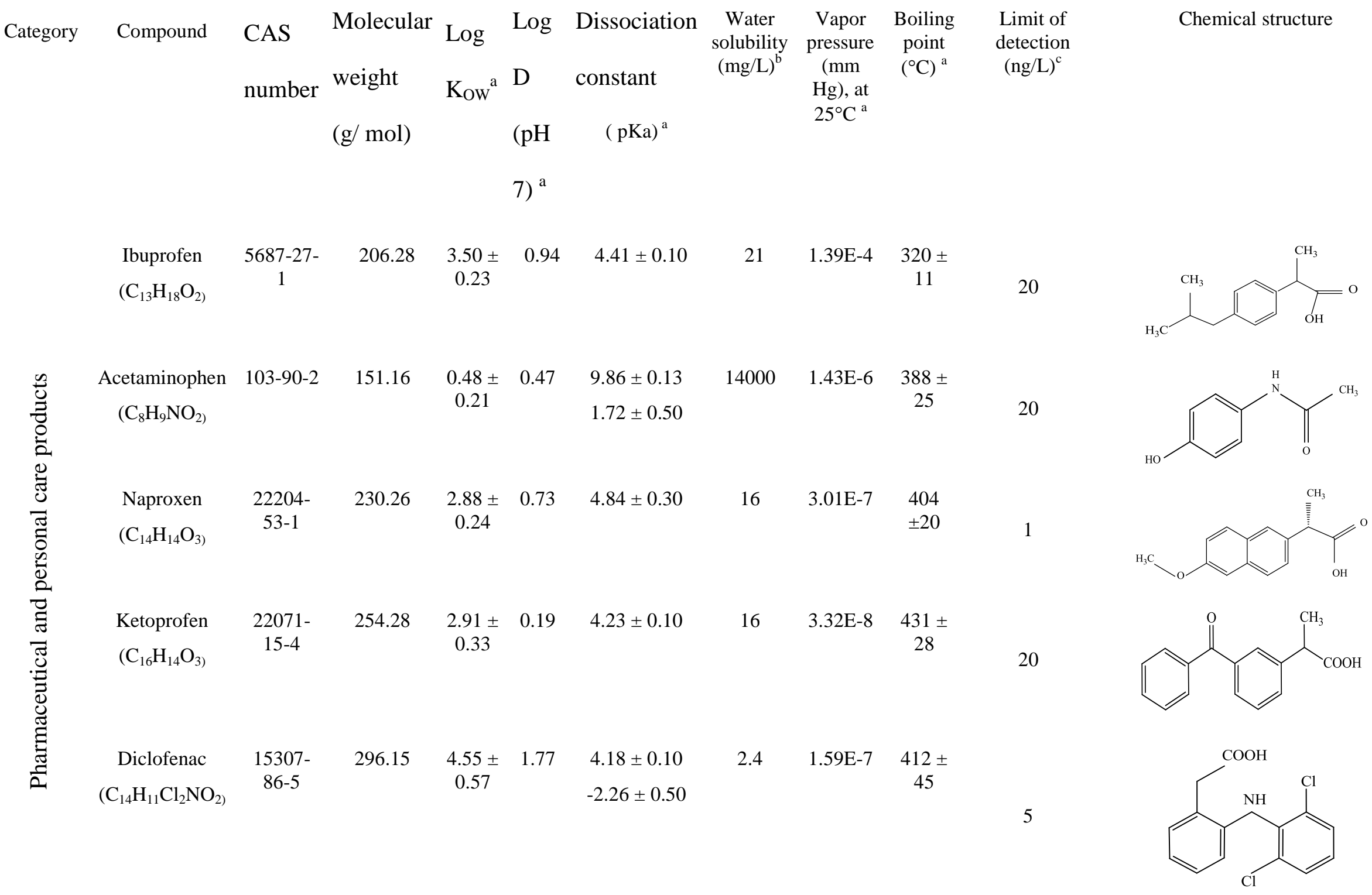




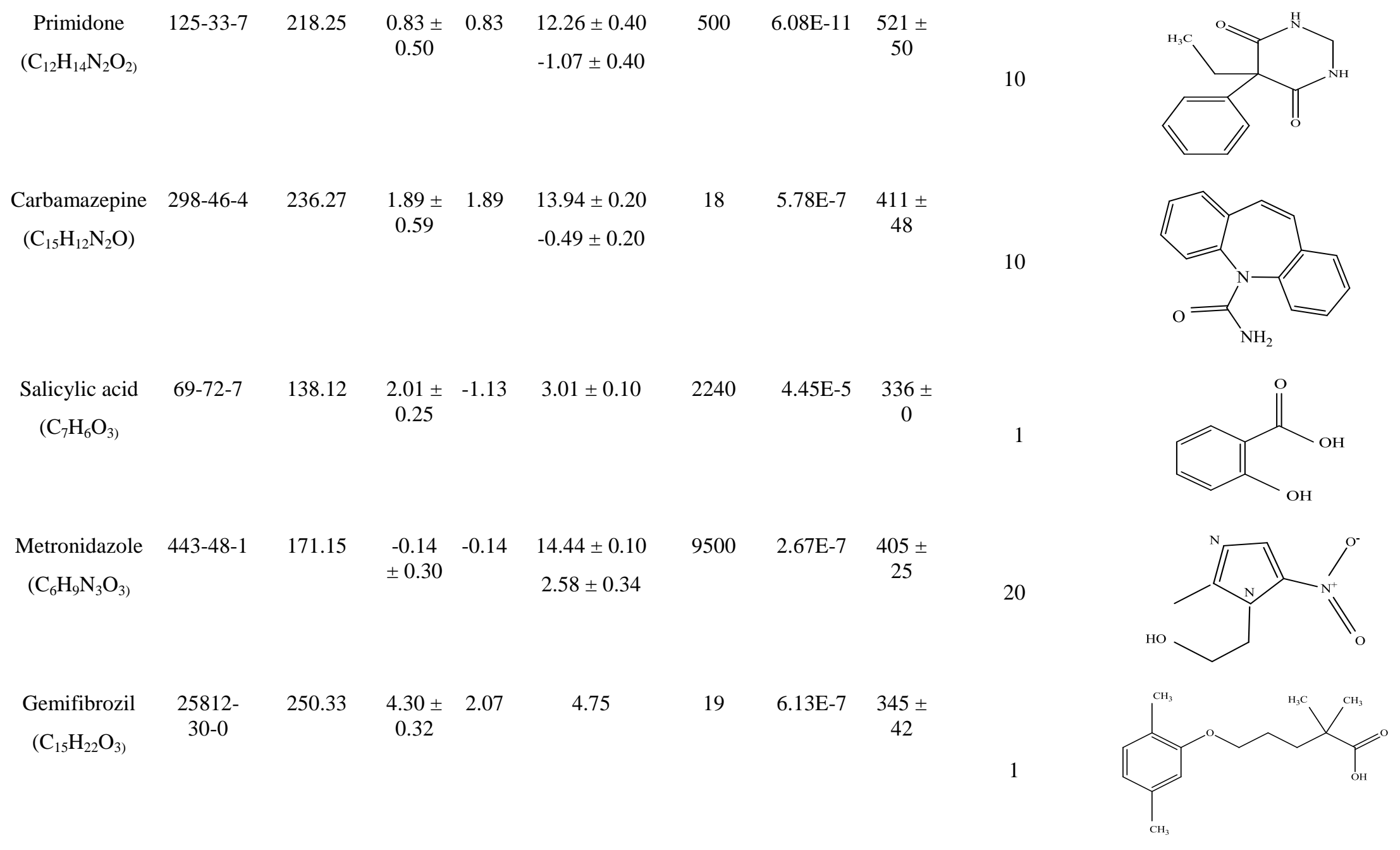




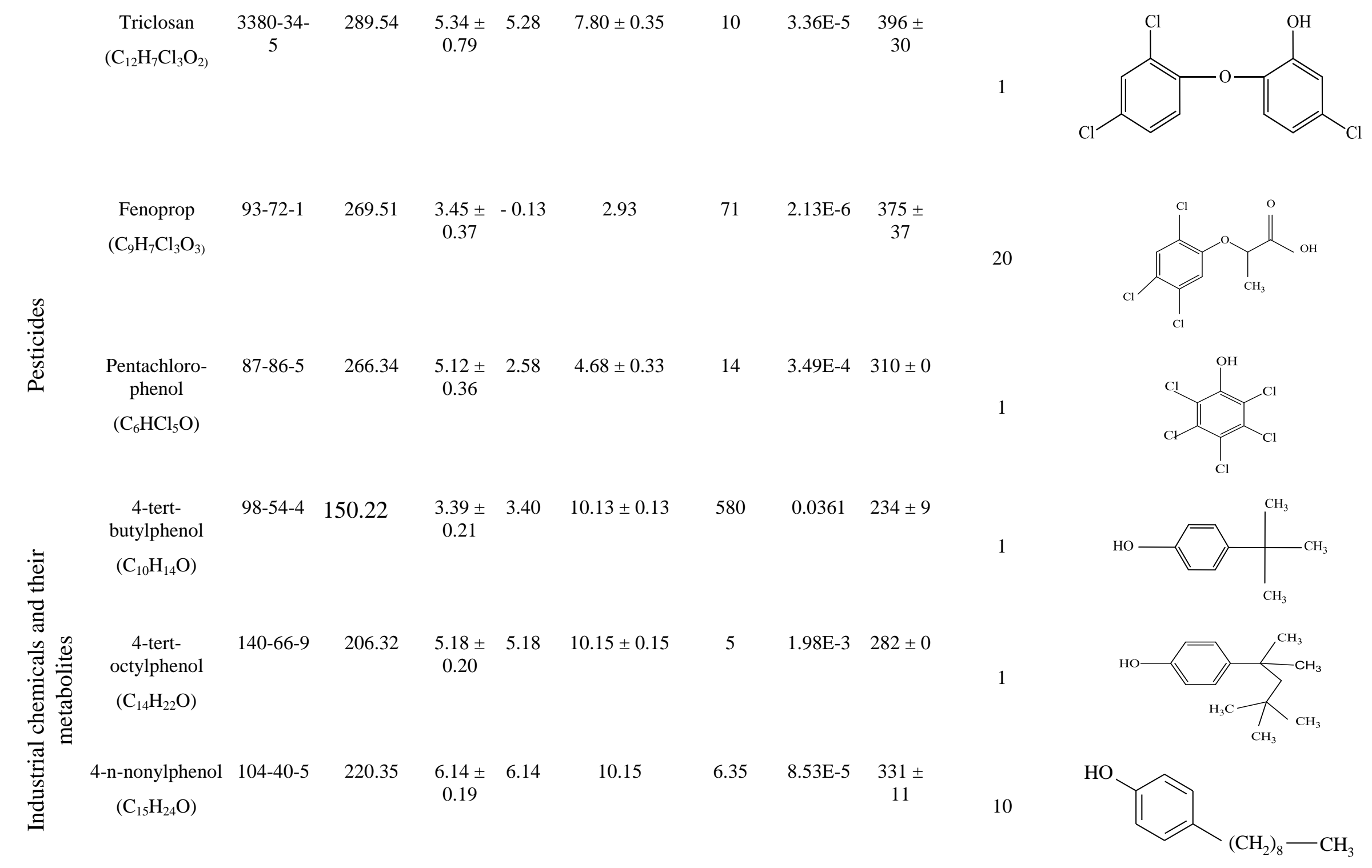




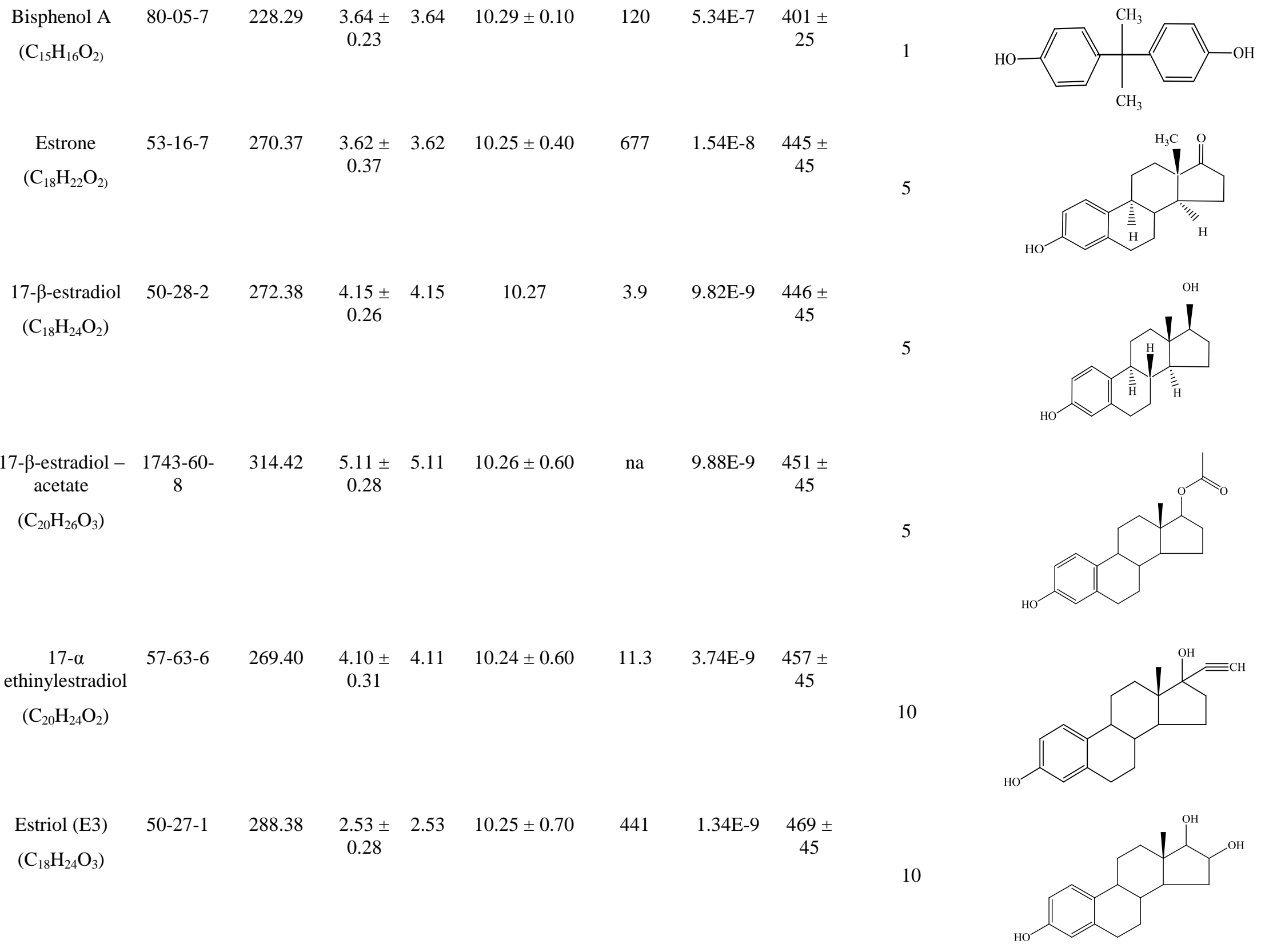


${ }^{a}$ Source: SciFinder database https://scifinder.cas.org/scifinder/view/scifinder/scifinderExplore.jsf

${ }^{\mathrm{b}}$ Source: http://chem.sis.nlm.nih.gov/chemidplus/

${ }^{\mathrm{c}}$ Limit of detection was defined as the concentration of an analyte giving a signal to noise $(\mathrm{S} / \mathrm{N})$ ratio greater than 3. The limit of reporting was determined using an $\mathrm{S} / \mathrm{N}$ ration of greater than 10 .

na: data not available 


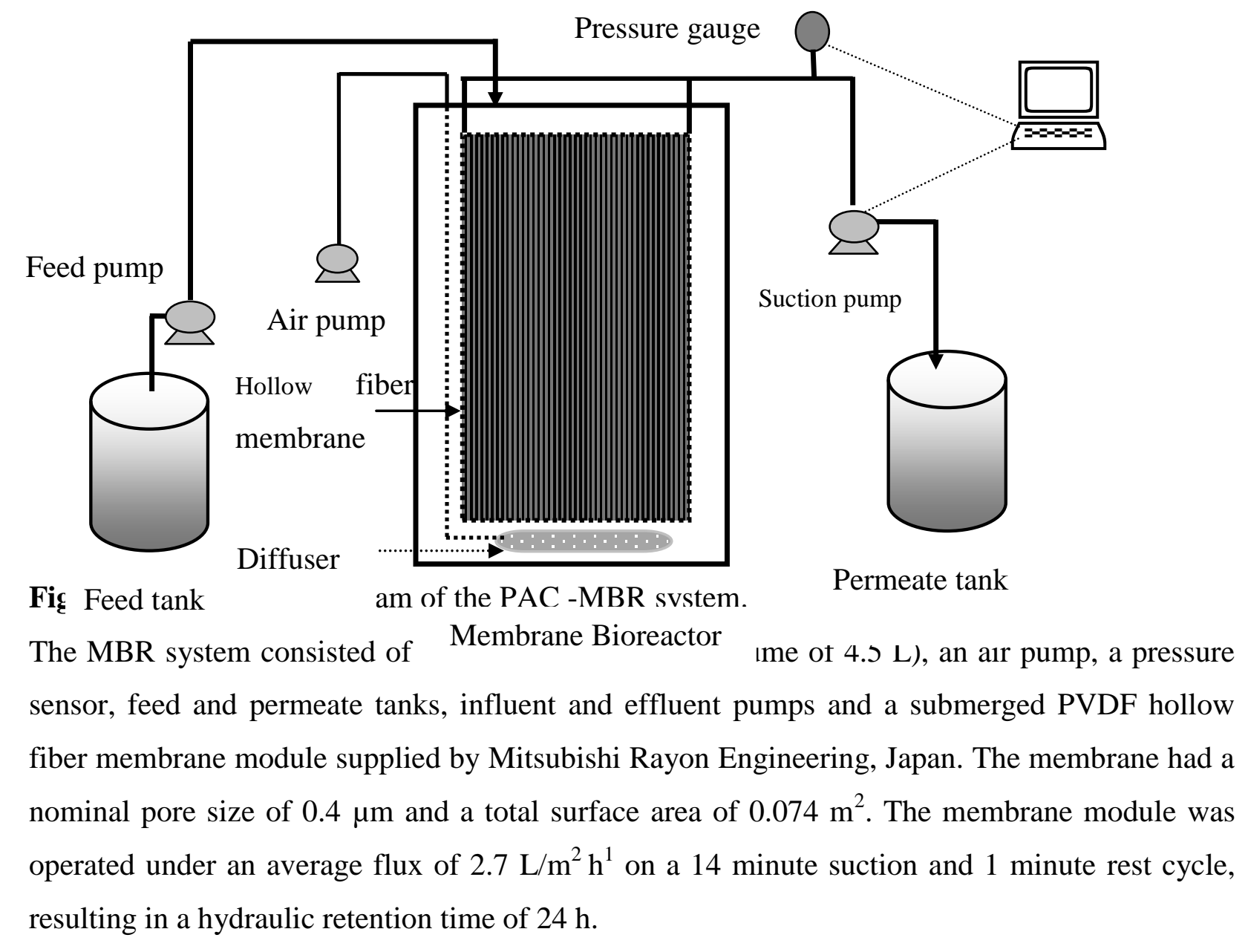


Table S3: Schedule of continuous operation of the MBR systems

\begin{tabular}{cll}
\hline Day & \multicolumn{1}{c}{ Operation mode } \\
\hline $0-51$ & MBR start- up period (without trace organics in feed) \\
\hline $52-196$ & Operation with trace organics in feed & \\
\hline $197-205$ & MBR-only & \\
\hline & MBR-only $($ stabilization period after sludge \\
\hline $206-242$ & withdrawal) & \\
\hline & & \\
\hline
\end{tabular}

After PAC addition, the PAC-MBR was operated in the same fashion as for MBR-only, with the operating conditions such as membrane flux, HRT, DO concentration, $\mathrm{pH}$ and temperature remaining the same. 


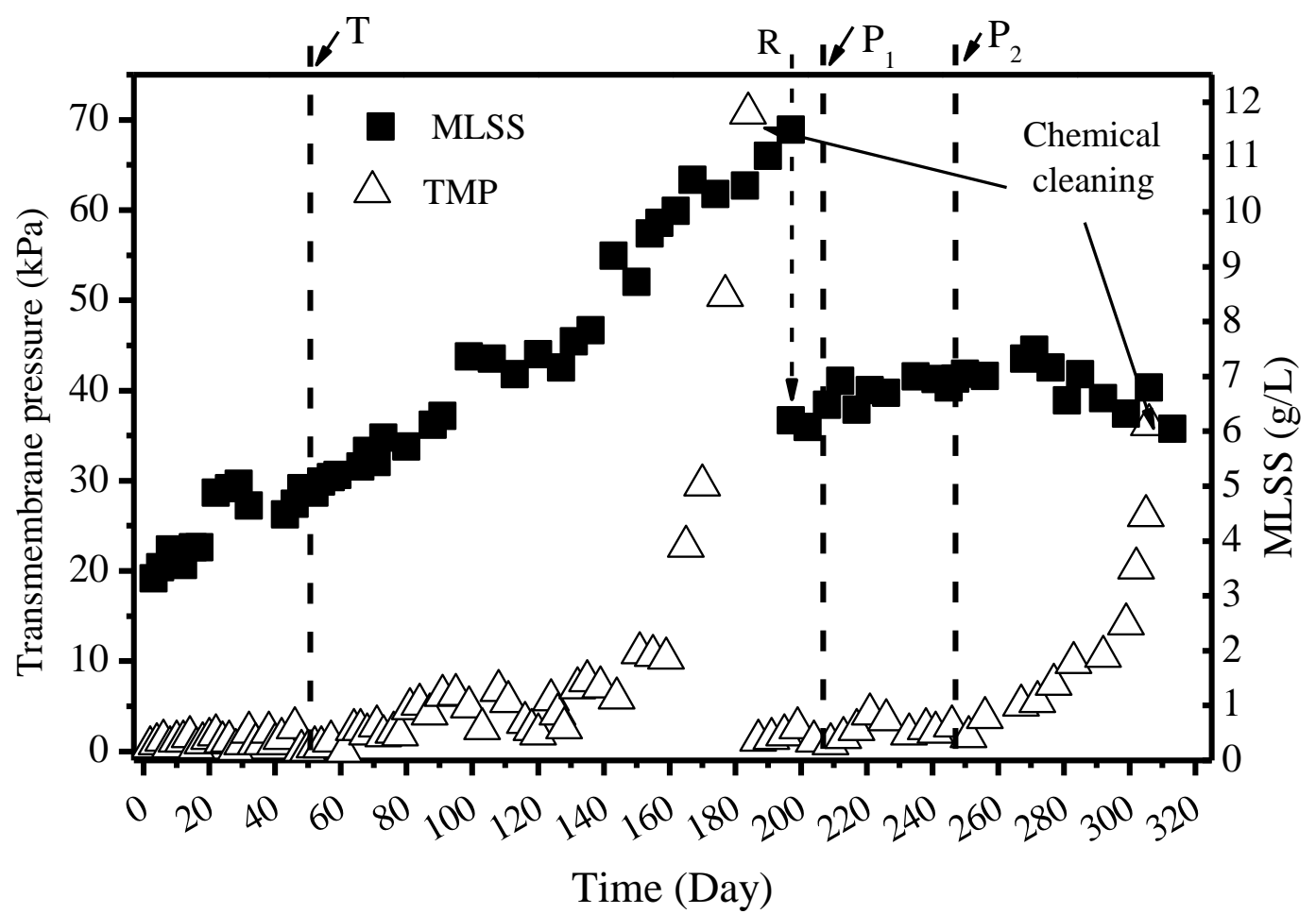

Figure S4: Variation of transmembrane pressure (TMP) as a function of operating time. "T" indicates the point of trace organic contaminant addition. " $\mathrm{R}$ " indicates the point of sludge withdrawal while " $\mathrm{P}_{1}$ " and " $\mathrm{P}_{2}$ " indicate the point of PAC addition to achieve final PAC $\begin{array}{lllllll}\text { concentrations of } & 0.1 & \mathrm{~g} / \mathrm{L} & \text { and } & 0.5 & \mathrm{~g} / \mathrm{L}, & \text { respectively }\end{array}$ 


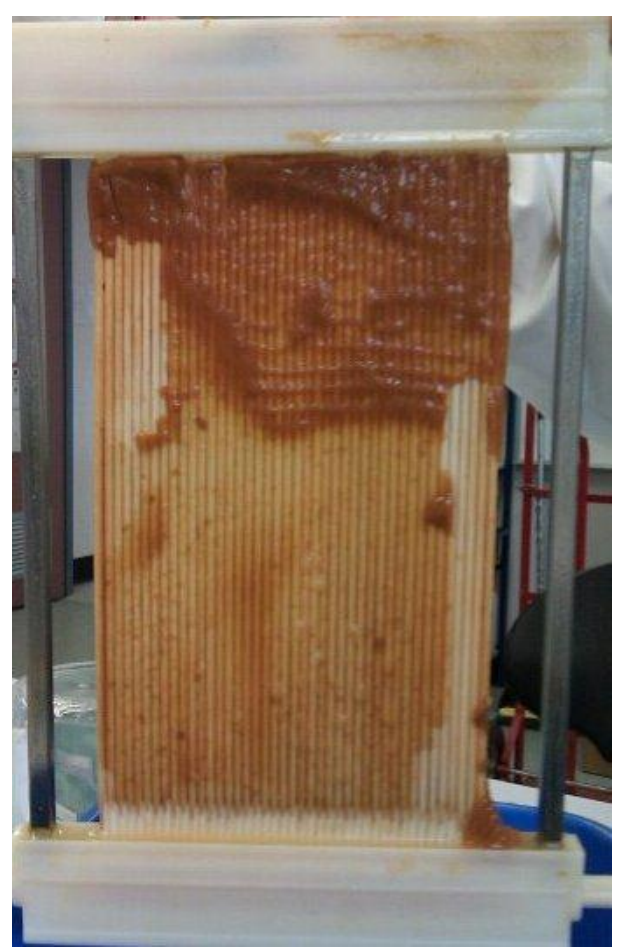

(a) Cake layer build up on the membrane surface in MBR system

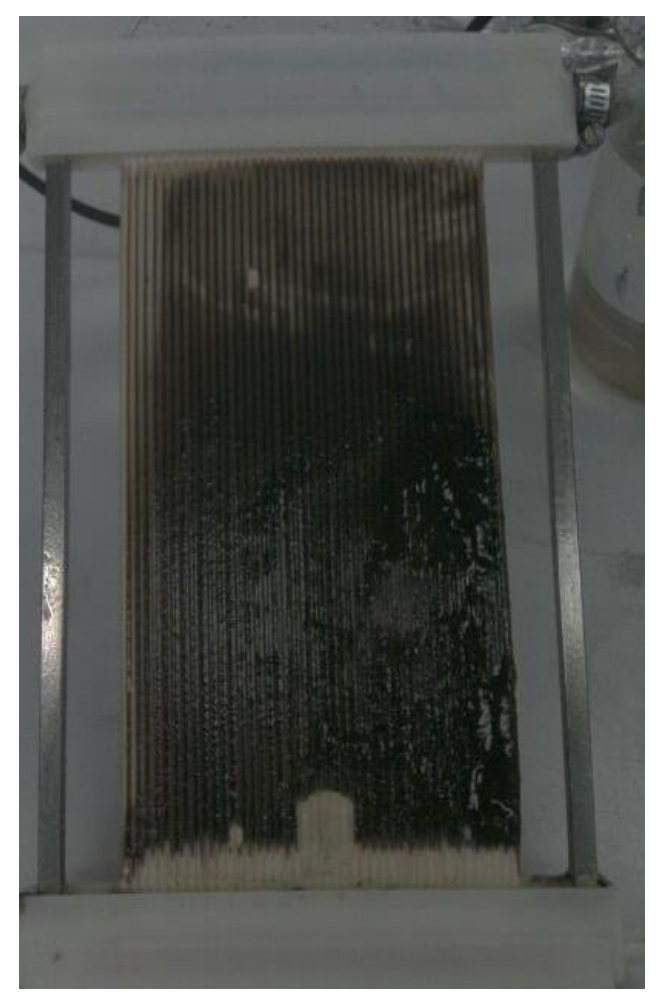

(b) Cake layer build up on the membrane surface in PAC - MBR system

Figure S5: Appearance of fouled membranes toward the end of operation of (a) MBR (Day 186) and (b) PAC - MBR (Day 306), respectively. Relatively greater coverage of cake layer in case of the PAC - MBR system is noticeable. 


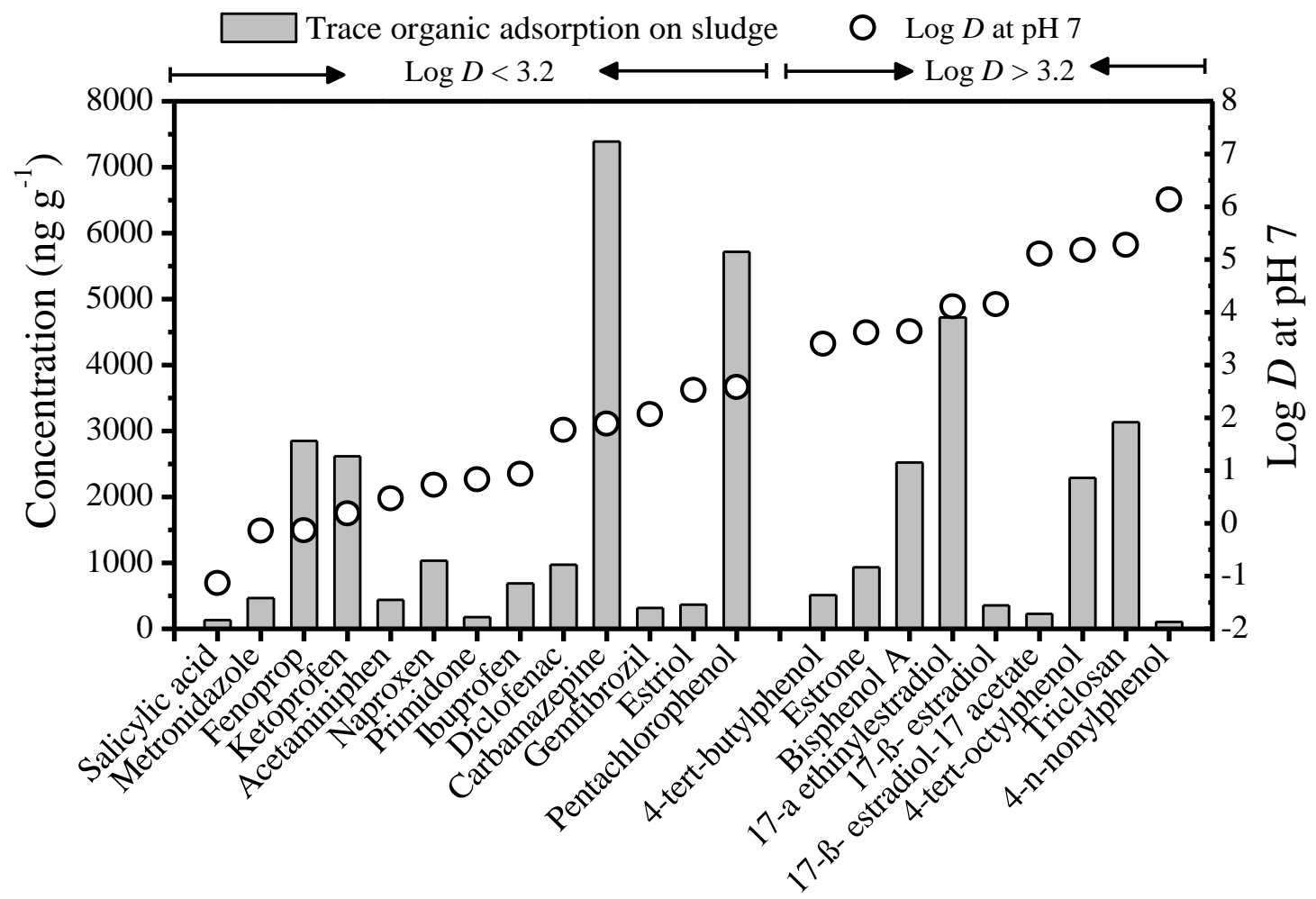

Figure S6: Adsorption of trace organic contaminants on PAC - MBR sludge. Extraction was conducted by using ultrasonic solvent extraction method. Sludge was collected from the reactor and then freeze dried for $4 \mathrm{~h}$. Sludge was ground to fine powder using mortar and pestle. $500 \mathrm{mg}$ of sludge was incubated with $5 \mathrm{~mL}$ methanol in a $13 \mathrm{~mL}$ glass culture tube. The slurry was well mixed by vortex mixer and unltrasonicated for $10 \mathrm{~min}$ at $40{ }^{0} \mathrm{C}$ and then centrifuged at $2851 \mathrm{x} \mathrm{g}$ for $10 \mathrm{~min}$. Decanted supernatant was collected and the remaining solid mixture was passed through another round of extraction process using $5 \mathrm{~mL}$ methanol and dichloromethane (1:1, V/V). Supernatants from all extraction steps were combined and diluted with Milli-Q water into $500 \mathrm{~mL}$. Solid phase extraction was carried out before measuring by GC/MS. 